\title{
Vías inflamatorias en la fisiopatología del acné
}

\author{
Inflammatory pathways in acne
}

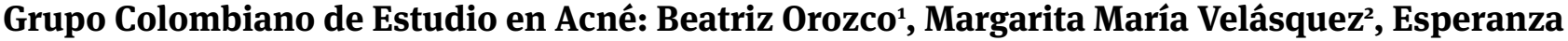 Meléndez ${ }^{3}$, Juan Guillermo Pabón, Adriana Motta, Liliana Anaya, Juan Jaime Atuesta, Luis Fernando Balcázar, María Isabel Barona ${ }^{4}$, Margarita María Becerra, Florinda Busi, Martha Helena Campo, Adriana Cruz, Milena Danies, Teresita Diazgranados, Diego Espinosa ${ }^{5}$, Claudia Escandón, Adriana Gaita, Gonzalo Eduardo García, Martha Lucía González, Bernardo Huyke, Sol Beatriz Jiménez ${ }^{5}$, Juana Gabriela López, María Cristina Lotero ${ }^{5}$, Óscar Medina, Carlos Montealegre², Mauricio Ortiz, Johanna Parra, Lina Quiroz ${ }^{5}$, Ramiro Quintero, Verónica Ranking, Jaime Rengifo ${ }^{6}$, Mary Ann Robledo², Ricardo Rueda, José Tovar, Claudia Uribe5, Jessica Vallejo, Gloria Velásquez ${ }^{5}$, Natalia Velásquez 5}

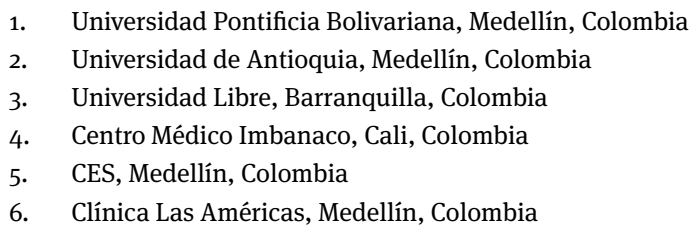

\section{Resumen}

El acné vulgar es una enfermedad inflamatoria multifactorial que compromete la unidad pilosebácea y afecta el 80 \% de la población adolescente. Se han propuesto diversos mecanismos en su patogénesis, entre los cuales se menciona, especialmente, el inmunológico posiblemente asociado al sobrecrecimiento bacteriano. En este artículo se revisan los avances más recientes de la fisiopatología e inmunología, la relación con Propionibacterium acnes y las posibles implicaciones terapéuticas.

PAlABRAS ClaVE: acné, inflamación, fisiopatología, inmunología, TLR-2
Correspondencia:

Beatriz Orozco

Email:

beatrizorozco@une.net.co

Recibido: 22 de abril de 2013.

Aceptado: 1 de Octubre de 2013.

No se reportan conflictos de intereses.

\section{Summary}

Acne vulgaris is a multifactorial inflammatory disease that involves the pilosebaceous unit, affecting $80 \%$ of the teenager population. Various mechanisms have been proposed in its pathogenesis, including special mention possibly an immunological mechanism associated with bacterial overgrowth. In this article we review the latest developments related to its pathophysiology and immunology, its relationship with Propionibacterium acnes and the possible therapeutic implications.

KEY WORDS: Acne, inflammation, physiopathology, immunology, TLR-2

\section{Introducción}

El acné vulgar es una enfermedad inflamatoria multifactorial de la unidad pilosebácea. Entre los mecanismos inmunopatogénicos propuestos, la activación de la res- puesta inmunitaria por agentes como Propionibacterium acnes, ha sido de especial interés y ampliamente estudiada por sus implicaciones terapéuticas. Propionibacterium acnes es capaz de disparar la respuesta inmunitaria innata y adaptativa tanto celular como humoral, 
mediante la liberación directa de productos proinflamatorios como proteasas, lipasas, hialuronidasas y factores quimiotácticos de polimorfonucleares, linfocitos y macrófagos. Este microorganismo también induce la liberación de citocinas al activar diferentes células mediante los receptores de tipo Toll (TLR). Entre las citocinas que participan en el acné, se resaltan la interleucina 1 (IL-1), el factor de necrosis tumoral alfa (TNF- $\alpha$ ), la IL-8, la IL10, la IL-12 y el interferón gamma (IFN- $\gamma)^{1,2}$.

La glándula sebácea se considera un órgano inmunológico, que tiene la capacidad de activar la inmunidad innata, producir neuropéptidos, excretar péptidos antimicrobianos y exhibir características de células madre. Los cambios cualitativos en los lípidos del sebo inducen alteración en la diferenciación de queratinocitos y en la secreción de IL-1, contribuyendo al desarrollo de hiperqueratosis folicular. Estos cambios pueden darse en respuesta a $P$. acnes y otros desencadenantes del acné. La presencia de metaloproteinasas se ha relacionado con alteración en la cicatrización. Las proteasas de $P$. acnes son inductoras de las metaloproteinasas (MMP) 1, 2, 3, 9 y 13; la MMP-9 está presente en el proceso de queratinización folicular. Estas metaloproteinasas son blancos terapéuticos en el acné ${ }^{3-6}$.

Los estudios recientes sobre la etiopatogenia del acné vulgar se han enfocado en el papel del daño oxidativo y las enzimas antioxidantes. Los neutrófilos reclutados en el tejido liberan especies reactivas de oxígeno, las cuales producen inflamación y daño tisular. Por otro lado, se han descrito los receptores activadores de proliferación de peroxisomas (Peroxisome Proliferator-Activated Receptors, PPAR), los cuales se expresan en la piel y pueden ser activados o bloqueados para modificar la producción de lípidos, la apoptosis de los sebocitos, el proceso inflamatorio y la diferenciación celular, ${ }^{7,8}$.

El estudio de los mecanismos que median la inflamación en el acné permitirá la identificación de nuevos blancos terapéuticos y, posiblemente, el diseño de herramientas de evaluación, la determinación de la gravedad en la enfermedad y el seguimiento.

\section{Propionibacterium acnes y su relación con la inflamación en el acné}

La patogénesis del acné es multifactorial y tradicionalmente se ha considerado que se basa en: 1) alteración de la queratinización folicular (hiperqueratinización) en la unidad pilosebácea; 2) colonización y actividad de P. acnes en los folículos; 3) influencia hormonal; 4) producción de sebo, y 5) liberación de mediadores de la inflamación.
Los recientes avances en estudios celulares y moleculares están cambiando la percepción de la patogénesis del acné, en la cual la respuesta inmunitaria cobra importancia, destacándose: 1) eventos inflamatorios mediados por la IL-1 que preceden a la hiperqueratinización; 2) P. acnes activa el sistema inmunitario innato mediante los TLR; 3) P. acnes induce la producción de metaloproteinasas y péptidos antimicrobianos (PAM), y 4) los lípidos de las glándulas sebáceas activan el sistema inmunitario innato9.

Propionibacterium acnes ha sido implicado en la patogénesis del acné por más de 100 años. Se ha documentado ampliamente cómo este microorganismo, que forma parte de la flora bacteriana normal de la piel y está presente en las lesiones de acné, juega un papel en la patogénesis de la enfermedad. Se ha evidenciado un incremento significativo de la población de P. acnes durante la pubertad, la cual es la edad de inicio de acné, y la mejoría del cuadro clínico después del tratamiento antimicrobiano ${ }^{10}$.

En los últimos años, algunos autores han cuestionado la importancia de $P$. acnes como agente causal, basados en estudios recientes en los que se encontraron concentraciones similares del microorganismo en los pacientes con acné y en los controles sanos ${ }^{11,12}$, lo cual evidencia que la gravedad de la inflamación no se correlaciona con las concentraciones bacterianas en los folículos ${ }^{13}$. Por otro lado, se ha demostrado que los antibióticos tienen efectos inmunomoduladores por sí mismos, independientes del efecto antimicrobiano ${ }^{10}$. Aunque aún no se ha esclarecido el papel exacto de P. acnes en la patogénesis del acné, sí hay amplia evidencia de su capacidad de activar el sistema inmunitario e inducir el fenómeno inflamatorio, tema central de esta revisión. Es probable que la respuesta diferencial e individual a $P$. acnes esté relacionada con la base genética y la presencia o no de acné ante este agente bacteriano.

Propionibacterium acnes es un bacilo Gram positivo, inmóvil, pleomórfico, bifurcado o ramificado, de crecimiento relativamente lento y no esporulado ${ }^{14}$. Posee una membrana celular y una pared celular rica en peptidoglucanos. Es un microorganismo esencialmente anaerobio, aunque en algunas condiciones puede tolerar el oxígeno. Se nutre de los ácidos grasos del sebo producido por las glándulas sebáceas. En la TABLA 1 se describe su taxonomía.

En los estudios serológicos y bioquímicos se diferenciaron dos fenotipos: tipo I y II, que aparentemente representan dos grupos filogenéticamente diferentes ${ }^{15}$. El tipo I, identificado en lesiones de acné, infecciones dentales y remplazos fallidos de cadera, fue objeto del primer análisis genómico ${ }^{14}$. La secuenciación del genoma de P. acnes (KPA171202) proveniente de aisla- 


$\begin{array}{ll}\text { Filo } & \text { Actinobacteria } \\ \text { Orden } & \text { Actinomycetales } \\ \text { Suborden } & \text { Propionibacterineae } \\ \text { Familia } & \text { Propionibacteriaceae } \\ \text { Género } & \text { Propionibacterium } \\ \text { Especie } & \text { P. acnes }\end{array}$

TABLA 1. Taxonomía del Propionibacterium acnes ${ }^{15}$.

mientos de piel, fue dada a conocer en el $2004{ }^{16}$ y ha permitido entender mejor el papel de esta bacteria en la fisiopatología de la enfermedad.

$\mathrm{Su}$ genoma es un cromosoma circular con 2'560.265 pares de bases que codifican alrededor de 2.333 genes, entre los que se encuentran los que le confieren su capacidad de crecer en medios anaerobios o microaerofílicos. La ausencia de genes relacionados con movilidad y la carencia de cascadas de quimiotaxis, confirman su condición de inmovilidad, aunque sí posee un sensor que responde a los estímulos del estrés oxidativo. Se han identificado múltiples genes que están potencialmente implicados en la inmunopatogénesis del acné. Por ejemplo, aquellos que codifican proteínas estructurales e inmunogénicas, como peptidoglucanos y proteínas (PPA1983, PPA1906), que participan en la adherencia a las células ${ }^{14}$.
No solamente los componentes estructurales de $P$. acnes son causales de la respuesta inflamatoria. Es claro que $P$. acnes juega un papel activo al sintetizar moléculas que inician la inflamación, ocasionan daño tisular y pueden hacer parte de los procesos de resistencia antibiótica. Por ejemplo, la generación de enzimas y porfirinas por $P$. acnes viables, es esencial en la iniciación de procesos inflamatorios, como se demuestra en los estudios en que se comparan las respuestas inmunitarias generadas por bacilos vivos y bacilos muertos ${ }^{1,2}$.

Con la secuenciación del genoma de $P$. acnes se evidenció que también sintetiza proteínas de choque térmico (Heat Shock Proteins, HSP), como GroEL y DnaK. Estas desempeñan un importante papel inmunogénico, demostrado en estudios donde actúan como agentes desencadenantes de producción de citocinas proinflamatorias, como la interleucina IL- $1 \alpha, \mathrm{TNF}-\alpha$ y el factor estimulante de colonias de Granulocitos y macrófagos (Granulocyte-Macrophage Colony-Stimulating Factor, GM-CSF) ${ }^{1}$.

En la TABLA 2 se resumen las moléculas sintetizadas por $P$. acnes implicadas en la inmunopatogénesis del acné.

El descubrimiento de bacteriófagos de $P$. acnes ha generado inquietudes acerca de su rol en la patogénesis del acné. Los fagos son los organismos más abundantes sobre la tierra y juegan un papel importante en la diversidad de las bacterias y en la patogénesis de enfermedades infecciosas. Ellos son virus que infectan

\begin{tabular}{|c|c|c|}
\hline $\begin{array}{c}\text { Moléculas con capacidad de daño } \\
\text { tisular }\end{array}$ & $\begin{array}{c}\text { Potenciales hemolisinas } 0 \\
\text { hemotoxinas }\end{array}$ & $\begin{array}{l}\text { Factores tisulares con potencial } \\
\text { toxigénico }\end{array}$ \\
\hline Triacilglicerol lipasa & $\begin{array}{l}\text { Factores CAMP (PPA687,PPA1198, } \\
\text { PPA1340, PPA2108) }\end{array}$ & $\begin{array}{l}\text { PPA1983, PPA1906 exhiben similitudes } \\
\text { a proteínas de superficie/ dominio } \\
\text { relevantes de adherencia }\end{array}$ \\
\hline \multicolumn{3}{|l|}{ Lisofosfolipasa } \\
\hline \multicolumn{3}{|l|}{ Cardiolipina sintetasa } \\
\hline \multicolumn{3}{|l|}{ Fosfoesterasa similar a la calcineurina } \\
\hline Hialuronato liasa & & $\begin{array}{l}\text { Envoltura celular basada en } \\
\text { lipoglucanos }\end{array}$ \\
\hline Endoglucoceramidasa & PPA 565 similar a hemolisina III & $\begin{array}{l}\text { Proteínas de choque térmico (HSP), } \\
\text { GroEL y DnaK }\end{array}$ \\
\hline $\begin{array}{l}\text { Sialidasa/neuramidasa } \\
\text { o-Sialoglucoproteína endopeptidasa }\end{array}$ & & Porfirinas \\
\hline \multicolumn{3}{|l|}{ Subtilisina extracelular similar a proteasa } \\
\hline Tripeptidil aminopeptidasa & & \\
\hline
\end{tabular}

CAMP: Christie, Atkins, Munch-Peterson. PPA: P. acnes

TABLA 2. Moléculas sintetizadas por $P$. acnes implicadas en la inmunopatogénesis del acné. 
bacterias, inyectando material genético de tipo ARN y ADN de cadena sencilla y doble (ssRNA, dsRNA, ssDNA o dsDNA). Hay fagos líticos, que infectan la bacteria y la destruyen, y hay lisogénicos, que integran su material genético al de la bacteria y pueden vivir con ella de forma silenciosa. En P. acnes se han secuenciado genes de un fago lítico (PA6) ${ }^{17} \mathrm{y}$ de fagos inducibles $\left(\mathrm{PAS}_{50}\right)^{18}$.

Los estudios de los fagos de P. acnes pueden ayudar a entender mejor esta bacteria desde el punto de vista genómico, a desarrollar métodos para manipularla genéticamente o a diferenciar subtipos de Propionibacterium $^{19}$. Esta área del conocimiento está en proceso de desarrollo; es clave continuar los estudios del genoma de los fagos y entender mejor cómo estos organismos influencian a la célula huésped y, asimismo, la patogénesis de la infección.

\section{Factores genéticos}

Hasta ahora se han estudiado pocos genes como factores de vulnerabilidad o predisposición al acné. Estos participarían en la regulación del metabolismo de las hormonas esteroideas, en la función inmunitaria innata de los queratinocitos epidérmicos o en ambas.

Se ha sugerido que el acné podría estar ligado a una homeostasis alterada, causada por aspectos de la vida moderna (estrés constante, sedentarismo, dieta), cuyos efectos pueden llevar a un aumento de la sensibilidad a los estímulos externos. Estos factores pueden aumentar la tendencia al desarrollo de enfermedades inflamatorias crónicas debido a pequeños cambios en el nivel de citocinas proinflamatorias o en el metabolismo hormonal y de otras moléculas, cambios que podrían originarse a partir de polimorfismos genéticos que afectan la expresión o la función de genes clave. Por ello, se necesitan estudios genéticos y moleculares sobre el papel del factor de crecimiento insulínico-1 (IGF-1), su receptor, la proteína 3 de unión del IGF y otros elementos de esta cascada, incluyendo receptores nucleares como: receptor X del hígado (LXR), receptor X del retinoide (RXR), receptor del ácido retinoico (RAR) y su cascada, entre estos el factor de transcripción Foxo1 ${ }^{20}$.

\section{Unidad pilosebácea}

La unidad pilosebácea es un órgano inmunocompetente. Está compuesta por queratinocitos y sebocitos que pueden actuar como células inmunitarias capaces de reconocer patógenos y también pueden tener anormalidades en sus lípidos. Todo lo anterior puede desempeñar un papel importante en iniciar y perpetuar la acti- vación de la respuesta inmunitaria innata y adaptativa ${ }^{21}$. Los agentes microbianos activan respuestas de citocinas por vía del TLR, que reconocen patrones moleculares asociados a patógenos y desencadenan la respuesta inmunitaria; se ha encontrado que $P$. acnes induce producción de IL-12 y de IL-8 por monocitos. Esta producción de citocinas puede ser inhibida por anticuerpos bloqueadores anti-TLR-2 ${ }^{22}$. Varios datos emergentes sugieren que estos eventos ocurren en estadios muy tempranos del desarrollo del acné, lo cual reabre el debate del potencial efecto de $P$. acnes en el inicio de esta enfermedad ${ }^{23}$.

Propionibacterium acnes aumenta la formación de lípidos intracelulares en sebocitos de hámster por incremento en la síntesis de novo de triacilgliceroles. Esto sugiere su asociación con la lipogénesis sebácea, la inflamación y la inmunidad innata. Así, los lípidos inducidos por $P$. acnes pueden representar un reclutamiento de factores protectores o agravantes ${ }^{24}$. Las glándulas sebáceas juegan un papel importante en la inmunidad innata de la piel, producen neuropéptidos y péptidos antimicrobianos, y exhiben características de células madre. Los cambios cualitativos en los lípidos del sebo inducen alteración en la diferenciación de queratinocitos y la secreción de IL-1, lo que contribuye a la hiperqueratosis folicular ${ }^{25}$.

\section{Inmunidad innata en el acné}

La inmunidad innata constituye la respuesta más temprana a cualquier patógeno. Comprende desde barreras físicas, como la piel y las mucosas, hasta respuestas celulares mediadas por monocitos y macrófagos, células asesinas naturales (Natural Killers, NK), células dendríticas, eosinófilos o basófilos, así como citocinas proinflamatorias y otros factores solubles ${ }^{22}$.

La respuesta inmunitaria innata desarrollada frente a P. acnes ha sido implicada como un factor importante en la patogénesis del acné y, por lo tanto, como posible objetivo en el tratamiento de esta entidad.

En la patogénesis del acné están vinculadas reacciones inflamatorias y colonización por P. acnes, el cual estimula a los queratinocitos para la producción de otros mediadores inflamatorios, por lo que se ha propuesto que el acné es el resultado de un desequilibrio en la respuesta inmunitaria innata de los queratinocitos que repercute en la intensidad de los factores intrínsecos bacterianos y de los factores endógenos del huésped ${ }^{26}$.

Entre los efectos descritos, $P$. acnes induce diferenciación de monocitos a macrófagos CD209+ y a células dendríticas $\mathrm{CD} 1 \mathrm{~b}+$, que tienen actividad antimicrobiana contra la bacteria fagocitada; por otro lado, induce la ex- 
presión de IL-15 y GM-CSF. La adición de tretinoína (ácido holo-transretinoico o ATRA), comúnmente usada para el tratamiento del acné, induce directamente la diferenciación de monocitos a macrófagos $\mathrm{CD} 209+\mathrm{y}$ potencia la diferenciación mediada por $P$. acnes en CD209+. Por lo tanto, la diferenciación de monocitos en macrófagos CD209+ y células dendríticas $\mathrm{CD1b}+$, por diferentes vías, media la respuesta inmunitaria innata a P. $a \mathrm{cnes}^{27}$.

\section{Péptidos antimicrobianos}

Los PAM son proteínas de más de 2,6 billones de años de antigüedad que hacen parte de los mecanismos de la inmunidad innata en la mayoría de los organismos vivos $^{28,29}$. En la piel, son producidos por los queratinocitos, neutrófilos, sebocitos y glándulas sudoríparas. Se expresan de manera constitutiva (RNase 7, psoriasin, dermcidin), o se sintetizan en mayor concentración ante un estímulo inflamatorio ( $\beta$-defensina-2 y 3 -catelicidina). El mecanismo de acción de los PAM no es completamente conocido, pero se cree que incrementan la permeabilidad de la membrana citoplásmica en el agente patógeno o alteran su estructura física ${ }^{28}$. También, hacen parte de cascadas de señalización en procesos inflamatorios o pueden servir de factores quimiotácticos para linfocitos $\mathrm{T}$ y células dendríticas.

La primera línea de defensa contra las infecciones son los PAM y la integridad de la barrera epidérmica. Además de lo anterior, la presencia de Staphylococcus epidermidis, el mayor constituyente de la microflora en la piel sana, actúa como barrera contra la colonización de potenciales patógenos como $P$. acnes, produciendo PAM que actúan conjuntamente con los PAM producidos por los queratinocitos, lo que permite mantener una homeostasis que regula el exceso de citocinas liberadas frente a los daños epidérmicos. La microflora cutánea normal tiene acción protectora, por lo que su desequilibrio, aun en ausencia de una infección clásica, podría tener asociación con entidades como el acné y la rosácea ${ }^{30}$.

Otro aspecto interesante es la actividad antimicrobiana de varios ácidos grasos libres en la piel. En modelos in vitro se demostró que los ácidos láurico, palmítico y oleico estimulan a los sebocitos para la producción de la $\beta$-defensina humana-2 (human $\beta$-Defensin 2, hBD-2), la cual tiene acción antimicrobiana contra $P$. acnes y sugiere el uso potencial de ácidos grasos libres como un tratamiento multifuncional antimicrobiano en el manejo del acné vulgar ${ }^{31}$.

Diferentes tipos de $P$. acnes inducen respuestas diversas por parte de los queratinocitos y sebocitos ${ }^{15,32}$, entre ellas, la habilidad de inducir la expresión de betadefensinas humanas (hBD), en particular, hBD-2. Si a esto se le adiciona la condición de sobrecrecimiento bacteriano en la unidad pilosebácea, se aumenta la probabilidad de desarrollar acné inflamatorio ${ }^{30,33}$. La inducción de la producción de beta-defensinas (hBD 1 y 2) ante el estímulo con $P$. acnes ${ }^{32,34}$, es consecuencia de la activación de la vía de señalización por los TLR 2 y 4. Los estudios con anticuerpos neutralizadores de TLR 2 y 4 han corroborado estas vías de activación de producción de PAM ${ }^{35}$. También, se ha demostrado que las beta-defensinas LL-37 y psoriasina, que se expresan en queratinocitos y sebocitos, tienen actividad microbicida contra P. acnes ${ }^{34,36,37}$.

\section{Reconocimiento bacteriano y receptores de tipo Toll}

Estos receptores (TLR) son uno de los principales mecanismos de reconocimiento de patógenos y esenciales en las primeras fases de la respuesta inflamatoria. Originalmente se encontraron en los genes de la mosca Drosophila que intervenía para la formación de su eje dorsal, pero luego se descubrió que también actuaban en la respuesta antimicrobiana en el reconocimiento de patrones conservados a lo largo de la evolución de muchos tipos de células, siendo esenciales en la respuesta inmunitaria innata ${ }^{38,39}$. Por lo tanto, los TLR intervienen en la respuesta inmunitaria en contra de bacterias, parásitos y hongos. Se encuentran localizados en el epitelio de la piel y de las vías aéreas, células endoteliales y células de la respuesta inmunitaria como son los monocitos, macrófagos, células dendríticas y granulocitos $4^{40}$.

Estos TLR se expresan en un amplio rango de células del sistema inmunitario de la piel, como queratinocitos, células de Langerhans, neutrófilos y monocitos. Son proteínas transmembrana, cuya porción extracelular está compuesta por repeticiones de leucina, mientras que su porción intracelular comparte homología con el dominio citoplásmico del receptor para la IL-1 ${ }^{41}$.

Se han descrito trece TLR entre los humanos y los ratones, que se denominan con números del 1 al 13, pero solo diez de ellos están presentes en los humanos. Los TLR tienen en común en su porción intracitoplásmica un dominio homólogo al receptor de la IL-1 denominado Toll/IL1 (TIR), mientras su porción extracelular está compuesta por repeticiones de leucinas ${ }^{42}$. Los TLR 2, 4 y 5 se encuentran localizados en las membranas celulares, mientras los TLR 3, 7, 8 y 9 se encuentran en las membranas endosómicas; los primeros reconocen patrones de patógenos extracelulares y, los segundos, ácidos nucleicos de los microbios ya fagocitados ${ }^{43}$.

Son múltiples los ligandos naturales de los TLR, e incluyen componentes de la pared celular bacteriana y material genético (TABLA 3). Por ejemplo, P. acnes, por ser una bacteria Gram positiva rica en peptidoglucano, 


\begin{tabular}{|c|c|}
\hline TLR & Ligandos \\
\hline 1 & Lipopéptidos triacilados bacterianos \\
\hline 2 & $\begin{array}{l}\text { Peptidoglucano, lipoproteína, ácido lipoteicoico y } \\
\text { porinas bacterianas, hemaglutinina vírica }\end{array}$ \\
\hline 3 & dsARN vírico \\
\hline 4 & $\begin{array}{l}\text { LPS de Gram negativos, mananos de hongos; } \\
\text { fosfolípidos de parásitos; proteínas de cubierta } \\
\text { de virus; proteínas de choque térmico }\end{array}$ \\
\hline 5 & Flagelina bacteriana \\
\hline 6 & $\begin{array}{l}\text { Lipopéptidos diacilados bacterianos y ácido } \\
\text { lipoteicoico }\end{array}$ \\
\hline 7 & SsARN monocateriano vírico \\
\hline 8 & ssARN monocateriano vírico \\
\hline 9 & ADN CpG sin metilar bacteriano y vírico \\
\hline 10 & Desconocido \\
\hline
\end{tabular}

LPS: lipopolisacárido de la pared bacteriana; CpG: secuencias citosina guanina; dsARN: ARN de doble cadena; ssRNA: ARN monocatenario

TABLA 3. Receptores de tipo toll (TLR) y sus ligandos.

es reconocida por la vía del TLR-2. El TLR-2 se encuentra presente en múltiples células de la respuesta inflamatoria, incluyendo queratinocitos y sebocitos ${ }^{35}$. La activación del TLR-2, genera una cascada de señalización intracelular, dependiente de la proteína de diferenciación mieloide (MyD88), que conduce a la translocación de factores nucleares, como la proteína activadora-1 (AP-1) y la proinflamatorias IL-1, IL-6, IL-8, IL-12 y TNF- $\alpha^{1,2}$.

Aunque la activación por su ligando extracelular sea diferente para cada TLR, la señalización de las vías de respuesta intracelular son similares en ellos a las utilizadas por los receptores de citocinas y terminan en la inducción de la translocación del factor nuclear kappa$\mathrm{B}$ (NF-kB), el cual modula la transcripción de muchos genes de respuesta inmunitaria. Esto resulta en la producción de multitud de citocinas y quimiocinas, además de la fabricación de péptidos antimicrobianos, y facilita la activación de la inmunidad adaptativa ${ }^{42}$.

El evento primario en la patogénesis del acné compromete la alteración del epitelio y la colonización de las unidades pilosebáceas por $P$. acnes. con la subsecuente reacción inflamatoria de la dermis circundante. La detección de células positivas para TLR-2 en la región perifolicular fue la primera prueba de que su activación contribuía a promover la respuesta inflamatoria y la actividad de la enfermedad. Esto, además, fue sustentado por la coexpresión de TLR-2 con CD14, que indica la presencia de células de la línea monocitos/macrófagos. Con los estudios desarrollados en ratones transgénicos, se pudo demostrar que el peptidoglucano de $P$. acnes es el ligando de los TLR-2 $2^{40}$.

Además, la activación de TLR-2 en los monocitos libera citocinas proinflamatorias como la IL-8 y la IL-12. La IL-8 es quimiotáctica para los neutrófilos; la liberación de enzimas lisosómicas por parte de estos, termina produciendo la ruptura de la unidad pilosebácea y aumenta la inflamación ${ }^{44}$. Por otra parte, la IL-12 promueve el desarrollo de la respuesta inmunitaria mediada por células Th1 y la sobreproducción de IL-12 se ha implicado en el daño tisular de varias enfermedades inflamatorias y autoinmunitarias ${ }^{45,46}$. Por lo tanto, la activación de los TLR-2 de monocitos, queratinocitos y otras células inflamatorias por el peptidoglucano de $P$. acnes, es posiblemente uno de los mecanismos iniciales de la respuesta inmunitaria innata en el acné y el que la conecta con la inmunidad adquirida ${ }^{40}$.

Los queratinocitos humanos de lesiones de acné expresan TLR-2 y TLR-4 de forma inducible desde las primeras horas de cultivo in vitro ${ }^{47}$. Usando diferentes cepas de $P$. acnes, se pudo demostrar que era posible activar la inmunidad innata y el crecimiento de queratinocitos. El incremento en la expresión del ARN mensajero de las $\beta$-defensinas y de la IL- 8 puede ser bloqueado con anticuerpos anti-TLR-2 y anti-TLR-4. Además, algunas de las cepas podían aumentar el crecimiento de queratinocitos in vitro y esto, posiblemente, podría explicar el taponamiento folicular dado por la hipercornificación y el proceso inflamatorio del acné ${ }^{35}$.

La respuesta de citocinas inflamatorias provocadas por $P$. acnes y mediada por los TLR intentando hacer un esfuerzo protector, por el contrario, produce un efecto deletéreo mediante la activación de la inflamación y destrucción del tejido. Teniendo en cuenta estas observaciones, la intervención terapéutica de los TLR ha llevado a la investigación de moléculas para tratar la enfermedad. El entendimiento de la inmunidad innata y de sus actores, como son entre ellos los TLR, seguirá siendo un pilar fundamental en la comprensión de la fisiopatología y la terapéutica del acné.

\section{Otras células que participan en inmunidad innata en acné}

Propionibacterium acnes posee una región ligando en su pared de péptidos que contiene LL diamino-pimélico y D-alanina, con dos residuos de glicina, combinados con grupos amino y carboxil, lo que desencadena la respuesta inmunitaria innata, induciendo a los monocitos a secretar citocinas proinflamatorias, incluyendo TNF- $\alpha$, IL-1 $\beta$ e IL-8. La IL-8, en asoció con P. acnes, induce factores quimiotácticos que atraen neutrófilos a la 
unidad pilosebácea y liberan proteasas, hialuronidasas y lipasas, las cuales contribuyen a la injuria de tejido ${ }^{2}$.

La cascada inflamatoria inducida por P. acnes está incrementada por los anticuerpos contra este patógeno y las citocinas proinflamatorias liberadas por estímulos de componentes de la pared de las células (complejos como polisacáridos-peptidoglucanos y el ácido lipoteicoico). Estos complejos generados en los folículos sebáceos, interactúan con los macrófagos del tejido durante la migración a través de la pared folicular intacta, y son reconocidos mediante las moléculas de superficie $\mathrm{CD} 14$ y TLR-2, lo que lleva finalmente a la producción de citocinas proinflamatorias que inducen la expresión de moléculas de adhesión vascular y dérmica, la quimiotaxis de células inflamatorias y la estimulación de otros mediadores inflamatorios como los leucotrienos y las prostaglandinas.

Lo anterior también se demostró en un estudio realizado en la India, con 50 pacientes de acné y 25 controles sanos, donde se determinó la producción de citocinas proinflamatorias de tipo IL- 8 y TNF- $\alpha$, GM-CSF, eI L12p40 por las células mononucleares de sangre periférica y los queratinocitos. Estos autores reportaron que $P$. acnes es capaz de inducir producción de las citocinas descritas en concentraciones mayores en los pacientes con acné que en sujetos sanos, siendo mayores en las formas más graves de acné. El principal productor de citocinas es el macrófago, seguido de los monocitos. El IFN- $\gamma$ juega un papel central en la inmunopatogénesis del acné, induciendo la expresión de E-selectina en las células endoteliales y las moléculas de adhesión intercelular (ICAM-1) y HLA-DR en los queratinocitos, los cuales están fuertemente expresados en las lesiones inflamatorias tempranas del acné ${ }^{24,25}$.

\section{Inmunidad específica en el acné}

En el acné se pueden comprobar fenómenos inmunológicos específicos, tanto de inmunidad celular mediada por linfocitos T como de inmunidad humoral mediada por anticuerpos. Propionibacterium acnes es capaz de poner en marcha estos dos tipos de respuesta, así como también de liberar directamente productos proinflamatorios como proteasas, lipasas, hialuronidasas y factores quimiotácticos para los polimorfonucleares neutrófilos, linfocitos y macrófagos. Es importante considerar a la unidad pilosebácea como un órgano inmunocompetente en el cual los queratinocitos y sebocitos pueden actuar como células inmunitarias capaces del reconocimiento de patógenos. Ambas células son activadas por $P$. acnes mediante TLR, moléculas CD14 y CD125,48.

\section{Inmunidad celular}

Existen diferentes controversias sobre el orden de aparición de dos eventos que forman parte de la fisiopatogenia del acné: inflamación e hipercornificación. En los últimos años se ha demostrado que el papel de $P$. acnes en la patogénesis del acné se basa en su contribución a los estados inflamatorios de la enfermedad. Sin embargo, luego de aceptar el papel de $P$. acnes, surge la duda de cuál es el evento inicial: la obstrucción del folículo que da paso a la inflamación o la inflamación.

En diferentes estudios se han demostrado que la inflamación precede la hipercornificación. La primera célula en aparecer es el linfocito $\mathrm{T}$, dejando atrás muchas versiones que le daban un papel protagónico al neutrófilo. La respuesta inicial es de hipersensibilidad de tipo IV a $P$. acnes. La célula comprometida es el LT-CD4 Th1, que aparece desde el inicio (menos de 6 a 24 horas); el neutrófilo aparece a las 72 horas, en $33 \%$ de las lesiones. El LT-CD4 está presente aun antes de existir alteraciones de la pared del folículo.

Confirmando el papel de la inflamación, como evento inicial, también tenemos la expresión de moléculas de adhesión vascular como, ICAM-1, E-selectina, VCAM-1, y la expresión de HLA-DR por células del infiltrado y expresión de ICAM-1 por queratinocitos de la pared folicular. Esto fue descrito en biopsias de pacientes sin acné, en folículos sin inflamación evidente de pacientes con acné y en pápulas inflamadas de menos de seis horas de evolución ${ }^{49}$. En estos estudios se evidenció un gran número de LT-CD4, la mayoría de los cuales eran linfocitos $\mathrm{T}$ de memoria efectora, y macrófagos alrededor de folículos que parecían no comprometidos en pacientes con acné, pero no se encontró ninguno en controles sanos. Además, había ausencia de neutrófilos y LT-CD8, y reducción del número de células de Langerhans en la epidermis perifolicular, en comparación con la de los controles sanos. No existía en ese momento la formación de microcomedones, demostrada por la integridad de la pared folicular por inmunomarcación con laminina y colágeno IV, lo que indicaba que el infiltrado inflamatorio era el evento inicial en la formación de la lesión de acné.

El hecho de encontrar gran cantidad de linfocitos $\mathrm{T}$ de memoria efectora, al contrario de lo que se observa en la piel normal, puede ser consecuencia de la regulación positiva de la E-selectina, el receptor para el posicionamiento de linfocitos en piel, lo cual permite la migración selectiva de células de este fenotipo hacia el tejido local. Estos estudios también sugieren que esta es una respuesta inmunitaria específica para el antígeno. Que el fenómeno inflamatorio es el evento inicial, se confirma aún más con el reporte de aumento de marcadores de tipo celular, 
vascular y de proliferación mediante exámenes de inmunohistoquímica ${ }^{50,51}$.

Los eventos tardíos en el desarrollo de lesiones inflamatorias incluyen el infiltrado de neutrófilos y la alteración de la pared del folículo. Esta respuesta inflamatoria disminuye, permitiendo la reparación del folículo mediante mecanismos de cicatrización. Un tercio de los individuos con acné sana de las lesiones de acné con cicatrices ${ }^{23}$.

Con relación al papel de $P$. acnes, también existe controversia. El número de bacterias viables dentro del folículo no muestra correlación con la gravedad de la inflamación y algunas lesiones inflamadas no tienen $P$. acnes viables ni hay relación con la reacción al tratamiento ${ }^{23}$. Sin embargo, se debe recordar lo que se expresó previamente, que $P$. acnes puede contribuir a la inflamación en el acné por activar TRL expresados en queratinocitos y sebocitos, los cuales liberaran citocinas proinflamatorias y aumentan la respuesta inflamatoria ya iniciada ${ }^{52}$. En estudios previos, se sugería que esta respuesta inmunitaria estaba relacionada con el tiempo y el grado de exposición a $P$. acnes, y que surgía como un evento tardío, y se concluyó que la respuesta ante esta bacteria depende de la respuesta inmunitaria del huésped ${ }^{28,29}$. Por otro lado, $P$. acnes se ha implicado en la iniciación de la respuesta inmunitaria mediada por células Th1, al activar la liberación de IL-12 por vía del TLR-2. Se describe que $P$. acnes estimula una respuesta inflamatoria por mecanismos mitogénicos y antigénicos; esos mecanismos incrementarían la inflamación mediante la activación de linfocitos $\mathrm{T}$ y liberación de citocinas. También, este microorganismo puede jugar un papel indirecto al estimular la liberación de IL-1 $\alpha$, TNF- $\alpha$ y GMCSF por los queratinocitos. Las citocinas mencionadas estimularían la respuesta inflamatoria y la inmunidad innata y adaptativa ${ }^{51}$.

Los antígenos de $P$. acnes estimulan la respuesta de linfocitos $\mathrm{T}$ y el hecho de que la membrana del folículo pilosebáceo se mantenga intacta podría sugerir un antígeno soluble, pero, como los productos solubles de $P$. acnes no son lo suficientemente antigénicos, lo relevante es la delgadez de la pared del folículo que le permite al bacilo estar en contacto con la célula de Langerhans. Este daño leve de la pared se debería a deficiencia de ácido linoleico, a causa de su dilución con la alta excreción de sebo dentro del folículo. Al el contacto con el bacilo, la célula de Langerhans se activa y migra al ganglio linfático para la presentación antigénica a los LT-CD4, iniciándose una respuesta inmunitaria adaptativa ${ }^{51}$.

La respuesta Th1 que estimula $P$. acnes es tan fuerte y capaz de producir citocinas como IL-12, IFN- $\gamma$ y el TNF- $\alpha$, que podría utilizarse como tratamiento antitumoral. Así, hoy se están realizando ensayos en melanoma ma- ligno con vacunas de $P$. acnes en modelos de ratón. No solamente induce respuesta Th1, sino que dirige la respuesta Th2 hacia Th1 ${ }^{53}$. Este cambio de Th2 a Th1 se está estudiando en dermatitis atópica; vacunas con bajas dosis de P. acnes han prevenido exitosamente las manifestaciones cutáneas de esta enfermedad en ratones ${ }^{54}$.

Ante la inflamación como evento inicial, también surge otra controversia: si el estímulo inicial es específico o inespecífico. En caso de ser específico, sería iniciado por proteínas inmunogénicas de P. acnes, al aumentar su población dentro del folículo. Estas proteínas serían procesadas por las células de Langerhans presentes en la pared folicular, la cuales son estimuladas por TNF- $\alpha$ y GM-CSF. Después de esto, las células de Langerhans migrarían al ganglio linfático local para presentar el antígeno a los LT-CD4, los cuales se activarían y migrarían a la piel. Dentro del folículo, la liberación de citocinas por estos linfocitos $\mathrm{T}$ produciría la ruptura del folículo y la inflamación visible. La ausencia de neutrófilos descartaría una respuesta específica para el antígeno. Las proteínas inmunogénicas de $P$. acnes son las proteínas HSP, que son fuertemente inmunogénicas y podrían ser liberadas por el estrés producido por el bacilo: al existir un mayor número de estas bacterias, aumentaría la producción de HSP que activaría a los LT-CD4 mediante la presentación por las células de Langerhans, lo cual correspondería a una respuesta específic para el antígeno que se confirma por la presencia por ARN mensajro de las citocinas Th1 en lesiones muy tempranas ${ }^{23}$.

La inmunidad celular no solo contribuye a la eliminación del antígeno, sino también al daño tisular. Se estudió el perfil inflamatorio de las lesiones de tipo pápula en la línea del tiempo: desde el inicio de la presentación clínica (lesiones de menos de seis horas de duración), durante su desarrollo (24 a 48 horas) hasta la resolución clínica ( 72 horas y seis a siete días de duración). Se valoró el número de LT-CD4 y la presencia de cicatrices. El número de LT-CD4 presentes en las lesiones de los pacientes con cicatrices, era la mitad en relación con los pacientes sin cicatrices. Sin embargo, un gran porcentaje eran linfocitos $\mathrm{T}$ de memoria efectora residentes en la piel, lo que sugiere que los pacientes que cicatrizaron eran más sensibles al antígeno causal. Las lesiones de menos de 6 a 48 horas, presentaban una mayor número de macrófagos, vasos sanguíneos y moléculas de adhesión vascular, tanto en el grupo con cicatrices como en aquel sin cicatrices, mientras que el número de células de Langerhans y la activación celular eran menores en el grupo con cicatrices, lo que indica una respuesta inefectiva contra el antígeno causal. En las lesiones en resolución clínica de los pacientes con cicatrices, había una regulación alta en la respuesta con mayor activación celular, y un posterior influjo de macrófagos y células $\mathrm{T}$ 
de memoria efectoras residentes en piel. La fuerte presencia del macrófago representa una fuerza dominante en esta respuesta, en los pacientes con cicatrices habría un antígeno que no se ha podido eliminar; el hecho de que $P$. acnes no es muy sensible a la fagocitosis y puede persistir dentro del macrófago por largos periodos, debe ser de relevancia ${ }^{51}$.

\section{Inmunidad humoral}

El acné es una enfermedad en la que intervienen los diferentes brazos del sistema inmunitario, destacándose principalmente la respuesta de hipersensibilidad retardada mediada por LT-CD4 Th1. Se conjugan, además, la respuesta inmunitaria innata y la respuesta humoral.

Desde inicios de los ochenta se describieron bacterias cubiertas por inmunoglobulina $\mathrm{G}$ ( $\mathrm{IgG}$ ) en el comedón, lo que sugería que esta IgG se derivaba del suero y se acumulaba selectivamente en el folículo ${ }^{55}$. Este hallazgo fue confirmado posteriormente, al identificarse anticuerpos en el suero de pacientes con acné, que reconocen un gran número de antígenos proteicos de $P$. acnes $^{49}$. Los anticuerpos contra el este bacilo se han encontrado frecuentemente en pacientes con acné y en algunos casos existe una correlación directa con su gravedad. Los anticuerpos son dirigidos contra enzimas de $P$. acnes o fracciones de la pared o membrana celular, tales como polisacáridos, carbohidratos o proteínas unidas a la membrana, en casos de acné. Estos presentan altos títulos de IgG1, de IgG2 y de IgG3 ${ }^{56}$. La presencia del anticuerpo sería importante para la inflamación porque, al ingresar al conducto dentro del folículo, donde sí hay anticuerpos, los neutrófilos liberan hidrolasas lisosómicas que contribuyen a la posterior ruptura del conducto ${ }^{57}$. Las recurrencias frecuentes podrían estar relacionadas con que los anticuerpos no producen suficiente protección contra los factores virulentos de la bacteria ${ }^{58,59}$.

Los trabajos de Knop y Holland han sido la inspiración en la búsqueda de una vacuna para esta enfermedad, en la que se cree que la supresión de P. acnes mediante anticuerpos específicos podría tener un potencial para prevenir su progresión y capacidad patógena ${ }^{55}$, revelando así la importancia de la inmunidad humoral en el acné. En experimentos recientes con modelos en ratón ${ }^{58}$, con $P$. acnes muertos por calor, se produjeron anticuerpos contra dos antígenos de $P$. acnes, proteínas de 64 y 250 $\mathrm{kDa}$. Estas vacunas de aplicación intranasal son capaces de suprimir el edema de la oreja de los ratones por 78 días. Otro dato interesante aportado por los trabajos que buscan una vacuna contra el acné, es que los anticuerpos contra $P$. acnes neutralizan efectivamente su citotoxicidad y disminuye la producción de IL-8 por los sebocitos humanos ${ }^{58}$. Otra proteína utilizada en vacunas ha sido la sialidasa del bacilo, teniendo en cuenta que esta ha sido usada en otras vacunas como contra la influenza y la neumonía bacteriana. Los resultados de Nakatsuji demostraron que los ratones inmunizados con sialidasa mostraban disminución del edema de la oreja inducido por $P$. acnes y se redujo la producción de citocinas proinflamatorias, como el TNF- $\alpha$. La sialidasa por sí sola no es inmunogénica pero, al desarrollar la vacuna con proteína recombinante, se transforma en inmunogénica ${ }^{59}$.

En cuanto al linfocito B, en un estudio de 20 pacientes con acné vulgar publicado en el 2007 por Lanosi, no se detectaron CD45-Ro del linfocito B mediante estudios de inmunohistoquímica ${ }^{60}$.

Al lado de la activación de la inmunidad humoral, está la del complemento. Se ha demostrado que tanto P. acnes como el contenido del comedón son capaces de activar el complemento por la vía clásica y la vía alterna. Utilizando inmunofluorescencia, se han detectado depósitos de $\mathrm{C}_{3}$ en los vasos de la dermis afectada por acné. En ocasiones, las inmunoglobulinas se observan al lado del complemento. La activación del complemento sería responsable de la conversión de una lesión no inflamada en una inflamada, porque genera productos como C3a $_{3}$ y $\mathrm{C}_{5}$ a. Esta conversión produce mediadores de la actividad inflamatoria, los cuales desencadenan los procesos inflamatorios, aumentando la permeabilidad vascular y produciendo el edema ${ }^{61}$.

\section{Citocinas que participan en la inmunopatogénesis del acné}

Como se describió previamente, en el acné, la respuesta del huésped a $P$. acnes resulta en la producción de citocinas proinflamatorias, como TNF- $\alpha$, L-1 $\alpha$ e IL-8, y explica varias de las manifestaciones clínicas de la enfermedad ${ }^{1,2,22,35}$. Además de presentar acciones que conllevan mayor inflamación, participan en los mecanismos de taponamiento folicular, como la hipercornificación del infundíbulo o hiperproliferación de los queratinocitos.

De manera reciente, se ha descrito que $P$. acnes es capaz de activar el sistema IGF-1/IGF-1R, lo que conduce a la estimulación de la proliferación de los queratinocitos ${ }^{38}$. Una dieta con alto índice glucémico también puede elevar los niveles séricos de IGF-1 y, en conjunto con el aumento de cargas bacterianas de $P$. acnes, pueden ser importantes en la generación de la lesión en piel ${ }^{38}$.

Además de IL-8, el sebocito expresa IL-1 $\alpha$, IL-1 $\beta$ e IL-6. También se liberan moléculas de adhesión vascular y 


\begin{tabular}{|c|c|}
\hline Citocina & Función principal \\
\hline IL-1 & $\begin{array}{l}\text { Mediador de respuesta inmunitaria; } \\
\text { hipercornificación del infundíbulo } \\
\text { folicular }\end{array}$ \\
\hline IL-8 & Quimioatrayente de neutrófilos \\
\hline TNF-a & Mediador de la respuesta inmunitaria \\
\hline IGF-1/IGF1R & Hiperproliferación de queratinocitos \\
\hline IL-12 & $\begin{array}{l}\text { Efectora de la respuesta inmunitaria } \\
\text { adaptativa }\end{array}$ \\
\hline IL-10 & Efecto antiinflamatorio e inmunosupresor \\
\hline INF- $\gamma$ & Mediador de la respuesta inmunitaria \\
\hline
\end{tabular}

TABLA 4. Citocinas en acné.

dérmica, se produce quimioatracción de células inflamatorias y se estimulan otros mediadores inflamatorios, como los leucotrienos y prostaglandinas. Las citocinas son reguladas por ectopeptidasas que se encuentran dentro del sebocito ${ }^{2,25}$.

En la TABLA 4, se detallan las principales citocinas implicadas en la patogénesis del acné.

\section{Interleucina 1}

Dentro del comedón se encuentran grandes concentraciones de IL-1 $\alpha$, responsables de inducir la hiperqueratinización en la pared del folículo pilosebáceo in vitro $\mathrm{y}$ en folículos piloseabáceos $\operatorname{sanos}^{23}$. Esta citocina es producida por queratinocitos y su alteración puede, a su vez, llevar a la liberación de esta. La difusión de esta IL-1 en la dermis subyacente causaría activación inespecífica de células mononucleares y endoteliales, permitiendo la inflamación y alteración del folículo ${ }^{23}$. La IL-1 $\alpha$ también se ha hallado alrededor de los folículos no comprometidos, lo cual indicaría un factor inicial. Esta puede aumentar la regulación de ICAM1, E-selectina y VCAM y, así, puede contribuir indirectamente a la migración de monocitos hacia la dermis perifolicular ${ }^{51}$. La IL-1 $\alpha$ también está presente en las lesiones inflamadas de menos de 6 a 72 horas de evolución en la dermis, epidermis y pared folicular, y se disminuye a los seis a siete días, lo cual sugiere que participa en la evolución de las lesiones $^{51}$. Esta citocina puede ser clave en la transformación de un folículo normal hacia la lesión de acné. Se cree que el estímulo para la liberación de la IL-1 $\alpha$ por el queratinocito, sería el cambio por dilución dentro del folículo y la disminución del ácido linoleico, por alterar la barrera dentro del folículo ${ }^{49}$. La espongiosis de la pared folicular, cambio que se demuestra tempranamente en los microcomedones, es consecuencia de la secreción de IL-1 a la dermis, que produce activación vascular. Es de tanta importancia la IL-1 en el acné, que se está buscando si existen polimorfismos como factor predisponente para desarrollar acné vulgar. Se ha encontrado una asociación positiva entre el alelo T de IL1A +4845 y el acné y, sus formas graves se asociaron con individuos que portan el genotipo homocigótico $\mathrm{T} / \mathrm{T}^{62}$.

\section{Interleucina 12}

Se halla junto al IFN-g y el TNF- $\beta$ en muchos folículos no comprometidos. Estas son citocinas típicas de LTCD4 Th1, que son efectores de la respuesta inmunitaria adaptativa y confirman aún más al acné como una alteración inflamatoria mediada por Th1 $1^{51}$. Propionibacterium acnes induce su liberación por células mononucleares periféricas y queratinocitos ${ }^{63}$. Hay controversia sobre esta citocina: en algunos estudios sobre el acné se encuentra aumentada y en otros no se modifica ${ }^{27,63}$. Propionibacterium acnes induce IL-12 e IL-8. Esta citocina activa células NK y células T citotóxicas ${ }^{53}$.

\section{Factor de necrosis tumoral alfa}

Propionibacterium acnes es capaz de inducir su liberación por células mononucleares y queratinocitos ${ }^{63}$. Su secreción está aumentada en el acné e induce la expresión de ICAM-1 y E-selectina. En la explicación de por qué algunos pacientes presentan acné y otros no lo desarrollan, cabría el papel de los polimorfismos y se resalta que el acné es una enfermedad poligénica, cuya expresión fenotípica representa la suma de muchos genes. Es posible que los polimorfismos para citocinas, como el TNF- $\alpha$ y la IL-1 $\alpha$, expliquen en parte la existencia de individuos propensos al acnés2.

En casos de lesiones de acné clínicamente inflamatorias, se describe una mayor expresión de genes de expresión de metaloproteinasas, beta-defensina 4, IL-8, granulisina y factor de transcripción NFkB (clave para la regulación de muchas citocinas). Los niveles de genes de ARNm de las citocinas reguladas por NFkB, como TNF- $\alpha$, IL-1B, IL-8 e IL-10, presentan aumento en la piel comprometida en comparación con la piel adyacente normal ${ }^{48}$.

En medios de cultivos de sebocitos con P. acnes y con lipopolisacáridos, se aumenta significativamente la producción de citocinas. Los lipopolisacáridos estimulan la IL-1 $\alpha$ y el TNF- $\alpha$. Propionibacterium acnes estimula solamente el TNF- $\alpha$. En medios de cultivo, este bacilo no tiene efecto sobre la liberación de IL-1 $\alpha^{25}$. El papel de esta citocina es mediado por TNF- $\alpha$; algunos estudios han propuesto que la variante del polimorfismo M196R, 
en el exón 6 de TFNR2, está asociada con hiperandrogenismo, lupus, osteoartritis, artritis reumatoidea y ovario poliquístico. Como se ha descrito en el texto, P. acnes induce liberación de citocinas a través de TLR-2; al evaluar los polimorfismos del receptor (TNFR2), los resultados sugieren que su genotipo puede influir en el hiperandrogenismo y el síndrome de ovario poliquístico, además de que sustenta la contribución de las citocinas en la patogénesis del acné. El polimorfismo en posición 308 del TNF- $\alpha$ puede predisponer al acné. El alelo 196R de FNTR2 es factor de riesgo para el acné en la población china ${ }^{64}$.

\section{Interferón gamma}

Su producción está aumentada por parte de los monocitos de sangre periférica de pacientes con acné, en comparación con los de voluntarios sanos ${ }^{65}$.

\section{Interleucina 10}

Su principal fuente son los macrófagos $\mathrm{CD} 14+$, las células $\mathrm{T}$ reguladoras $\operatorname{Tr} 1$ y las células Th2, las cuales median la tolerancia periférica. También es producida por linfocitos B y es expresada por queratinocitos en presencia de radiación ultravioleta. Inhibe la función de macrófagos y células dendríticas, disminuyendo la presentación de antígeno y la producción de citocinas, quimiocinas, óxido nítrico, especies reactivas de oxígeno y moléculas coestimuladoras. Tiene efectos antiinflamatorios e inmunosupresores porque inhibe la proliferación y activación de los linfocitos $\mathrm{T}$, inhibiendo la célula de Langerhans. También, inhibe el ICAM-1 y es un regulador de la respuesta inflamatoria que limita el daño al tejido del huésped por efecto del sistema inmunitario en respuesta al patógeno microbiano ${ }^{66}$.

Inhibe fuertemente la producción de IL-12 en la piel. Los niveles de IL-10 aumentan en los comedones después de la radiación ultravioleta e inducen deficiencia funcional de las células presentadoras de antígeno, incluyendo la célula de Langerhans. Esto puede explicar por qué hay pacientes que mejoran con la radiación ultravioleta ${ }^{66}$.

Se ha confirmado que en el acné hay disminución de la producción de IL-10 por los monocitos de sangre periférica $y$, al agregar IL-10 a monocitos de sangre periférica en casos de acné, se restaura la actividad fagocítica. Actúa principalmente sobre el TNF- $\alpha$, pero tiene poco efecto sobre la IL-12. Se puede decir que una deficiencia de IL-10 predispone al paciente a tener acné, pero no puede predecir su gravedad. La IL-10 aparece posteriormente en las lesiones establecidas para regular la respuesta inflamatoria. Se ha propuesto que la deficiencia de esta citocina podría deberse a factores genéticos ${ }^{63}$.

\section{Interleucina 8}

Su secreción está aumentada en casos de acné. Propionibacterium acnes estimula su liberación en medios de cultivo de sebocitos de pacientes con acné y hay una fuerte expresión de IL- 8 en relación con controles sanos. Además, la hormona liberadora de corticotropina aumenta la liberación de IL-6 y la liberación de IL-8 de los sebocitos in vitro también se aumenta por los liposacáridos componentes de bacterias Gram negativas y Gram positivas ${ }^{25}$.

La IL-8 es un péptido activador y quimiotáctico de los neutrófilos. A mayor hiperplasia epidérmica e hiperqueratosis, hay mayor cantidad de IL-8 y gravedad de la enfermedad. La IL-8 se relaciona con muchos tipos de células, como monocitos, macrófagos, fibroblastos y linfocitos T. La IL-8 atrae neutrófilos que, al degranularse, liberan serinproteasas, catepsina G, elastasa de leucocitos y proteinasas en el sitio de la inflamación, lo que genera la liberación de más IL-8 y nuevos receptores de esta citocina, perpetuando la inflamación.

Se ha sugerido que los cambios en los vasos sanguíneos de la dermis papilar o de la región interfolicular, juegan un papel importante, ya que pueden producir citocinas proinflamatorias que modulan la inflamación. La IL-8 puede ser un factor de crecimiento de las células endoteliales. El mecanismo de regulación de la angiogénesis por la IL-8, puede deberse en parte a la proliferación y supervivencia de las células endoteliales por la expresión de genes antiapoptósicos y, en parte, por la activación de metaloproteinasas 2 y 9 . El bloqueo de la IL-8 tiene un potencial terapéutico ${ }^{67}$.

\section{Metaloproteinasas}

Las metaloproteinasas de matriz, o matrixinas, son proteínas multidominio cuya función es degradar las proteínas de la matriz extracelular. Su regulación bajo condiciones fisiológicas les permite participar en procesos biológicos como la morfogénesis, la cicatrización y la reparación de las heridas. Sin embargo, cuando este control falla aparecen múltiples enfermedades como arterioesclerosis, estenosis, aneurismas, hipertrofia ventricular izquierda o falla cardíaca ${ }^{68}$.

La estructura básica de las metaloproteinasas está conformada por una serie de dominios característicos: un péptido señal que dirige la secreción al exterior de la célula, un propéptido que mantiene a la enzima inactiva hasta que sufre un corte proteolítico y un dominio catalítico carboxi-terminal que une cinc. Sobre esta estructura básica aparecen diversas variantes, como un dominio de tipo hemopexina, que media en la especificidad del sustrato y las interacciones con inhibidores 


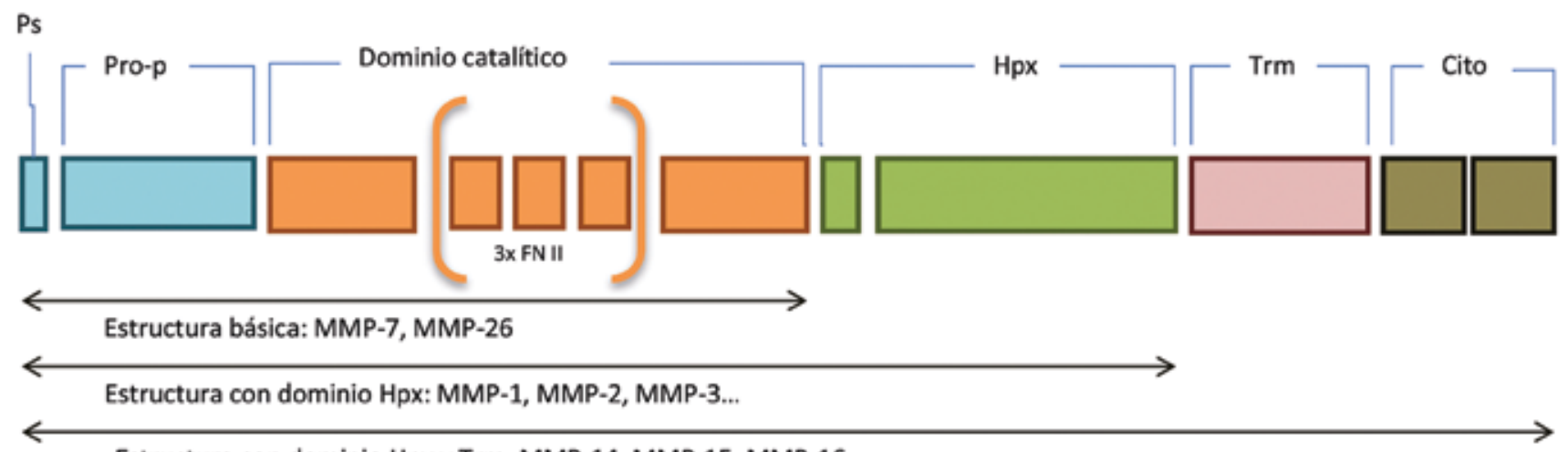

Estructura con dominio Hpx y Trm: MMP-14, MMP-15, MMP-16

Ps: péptido señal; Pro-p: propéptido; Hpx: dominio de tipo hemopexina; Trm: dominio transmembrana; Cito: dominio citoplasmático; FN II: fibronectina de tipo dos.

FIGURA 1. Estructura general de las metaloproteinasas (MMP).

endógenos, o un dominio transmembrana, en el caso de las metaloproteinasas asociadas a la membrana plasmática $^{62}$ (FIGURA 1).

En los humanos hay 24 genes productores de metaloproteinasas, pero uno de ellos se encuentra duplicado por lo que realmente son 23. La actividad de las metaloproteinasas es muy baja en los tejidos normales y la transcripción está controlada por citocinas, factores de crecimiento, hormonas, interacciones célula a célula y célula matriz.

Se enumeran en forma consecutiva del número $1 \mathrm{al} 28$, pero no se tienen en cuenta la 4, la 5, la 6 ni la 22, puesto que son idénticas a otras descritas. Aunque las metaloproteinasas se describen como extracelulares, tres se encuentran intracelulares y actúan sobre proteínas intracelulares (la 1, la 2 y la 11). Se clasifican según la preferencia del sustrato y la organización de los dominios en colagenasas (la 1, la 8, la 13 y la 18), gelatinasas (la 2 y la 9), estromelisinas (la 3, la 10 y la 11), matrisilinas (la 7 y la 26), metaloproteinasas transmembrana (la 14, la 15 , la 16 , la 17 y la 24 ) y no agrupadas (la 12 , la 19, la 20, la 21 , la 23 , la 27 y la 28$)^{68}$.

\section{Activación de las metaloproteinasas}

Las metaloproteinasas se sintetizan como pre-proenzimas. El péptido señal se pierde durante la translación y se genera la metaloproteinasa como un cimógeno o como una prometaloproteinasa. Trece de las metaloproteinasas se secretan de esta forma y pierden parte del propéptido por proteinasas plasmáticas o de bacterias oportunistas; la otra parte del propéptido se elimina por la acción de una metaloproteinasa intermedia u otra que ya esté activada. Las otras 10 metaloproteinasas son activadas intracelularmente y secretadas como enzimas activas. Muchas también se activan con compuestos mercuriales por perturbación de la molécula y con oxidantes que reaccionan con la cisteína.

\section{Dominio no catalítico}

El dominio no catalítico es el que determina la especificidad del sustrato.

La fibronectina de tipo II es importante en las gelatinasas para romper el colágeno IV, las elastinas y las gelatinasas.

La hemopexina es esencial para la actividad colagenolítica de las colagenasas. Es decir, sin este dominio hemopexina no se podría romper la estructura de triple hélice del colágeno.

\section{Inhibición de las metaloproteinasas}

Las actividades de las metaloproteinasas están inhibidas por dos inhibidores endógenos: la $\alpha 2$ macroglobulina y los inhibidores tisulares de metaloproteinasas (TIMP). La macroglobulina es una glucoproteína plasmática que forma un complejo con las metaloproteinasas y este complejo es tomado por un receptor de lipoproteínas de baja densidad mediante endocitosis. Los TIMP son proteínas constituidas por 184 a 194 aminoácidos y poseen dos dominios, uno $\mathrm{N}$ terminal y uno $\mathrm{C}$ terminal. Gracias a estos, se unen a las metaloproteinasas e inhiben sus acciones ${ }^{68}$. 


\section{Metaloproteinasas y acné}

En cuanto a la presencia de las metaloproteinasas en el acné, en algunos estudios se ha descrito que en el sebo de los pacientes se encuentra proMMP-9, MMP-1 como proMMP-1 y, además, MMP-13 ${ }^{69}$. También, se detectó TIMP-1 y TIMP-2. Posiblemente el origen de estas gelatinasas, colagenasas y sus inhibidores, sean los queratinocitos y sebocitos, lo cual se demuestra por la expresión y secreción de proMMP-2 y proMMP-9 por parte de queratinocitos HaCaT y sebocitos SZ95 cultivados y, de MMP-1, MMP-13, TIMP-1 y TIMP-2, por los queratinocitos ${ }^{69}$. En otro estudio de lesiones de acné, se demostraron células que expresaban MMP-1 y MMP-9 en los infiltrados inflamatorios dérmicos y perifoliculares e, in vitro, la inducción por parte de $P$. acnes del ARNm de MMP-1 y MMP-9, y la expresión de este último ${ }^{70}$.

Otros autores, mediante técnicas de microarreglos y PCR en tiempo real, demostraron la presencia de MMP-1 y MMP-3 en lesiones de acné ${ }^{71}$.

Tratando de determinar los posibles factores que inducen la producción de las metaloproteinasas, uno de los más estudiados ha sido P. acnes. Se ha observado que esta bacteria anaerobia estimula la producción de proMMP-2 en sebocitos de hámster y fibroblastos dérmicos humanos, y que el peptidoglucano de esta bacteria por sí solo lograba inducir la misma respuesta en estos grupos celulares ${ }^{6}$. Además, se ha reportado que $P$. acnes indujo en los fibroblastos dérmicos activación de la vía NF-kB que generaba aumento en la transcripción de TNF- $\alpha^{3}$. Esta sustancia, a su vez, estimulaba la producción de proMMP-2. Además del peptidoglucano, las proteasas de este bacilo se han visto implicadas como inductoras de las metaloproteinasas 1, 2, 3, 9 y 13.

La presencia de metaloproteinasas se ha implicado como causa de alteración en la cicatrización en el acné; por esta razón, se han realizado estudios para determinar si los medicamentos que convencionalmente se usan en esta enfermedad las modifican. Dentro de la aplicación terapéutica que se le puede dar a estos hallazgos, está la acción descrita para las tetraciclinas, demostrándose que inhiben la MMP-9, enzima presente en el proceso de queratinización folicular 4,5 .

Con respecto al efecto de los retinoides, se ha demostrado que la isotretinoína reduce la actividad de la MMP-9 y la secreción de MMP-13 en el sebo de pacientes con acné, independientemente de la vía de administración, y este efecto es mayor según la duración del tratamiento y está en paralelo con la mejoría del cuadro clínico. Igualmente, se ha observado disminución de las prometaloproteinasas 2 y 9 en cultivos de queratinocitos y sebocitos, además de inhibición de la expresión del ARNm de MMP-969. El tratamiento conjunto de monocitos con tretinoína (ácido holo-transretinoico o ATRA) y P. acnes inhibió la inducción de esta bacteria de MMP-1 y MMP-9, mientras que aumentaba la expresión de TIMP-1 ${ }^{70}$.

Otros tratamientos enfocados a inhibir la formación de sebo se vienen desarrollando en modelos animales, como la utilización de luz azul de $420 \mathrm{~nm}$ que tiene efecto inhibitorio sobre la MMP-2, y el mismo efecto de la clindamicina y la norfloxacina sobre la prostanglandina E2 (PGE2) y la MMP-2 descrito en hámsters.

\section{Radicales libres en acné}

El estrés oxidativo es un término usado para indicar el desequilibrio entre la concentración de radicales libres de oxígeno y la concentración de mecanismos de defensa antioxidantes. El estrés oxidativo causado por el aumento de la producción de oxígeno en las células, inicia un proceso degenerativo y altera la homeostasis celular. Los radicales libres resultantes llevan a la inflamación de la piel. Los organismos aerobios utilizan moléculas de oxígeno para el catabolismo de otras moléculas ricas en carbono e hidrógeno, y para producir la energía química y carbónica requerida para su supervivencia. Los radicales libres con actividad tóxica son generados durante el consumo de oxígeno, particularmente en las células. Producen alteraciones en las funciones celulares, las cuales varían según el tiempo y la duración de la exposición ${ }^{8}$.

La piel está expuesta a estrés oxidativo inducido por especies reactivas de oxígeno (ROS), que son generadas por fuentes endógenas tales como la actividad enzimática o neutrófilos activados y estímulos externos como la radiación ultravioleta. El daño oxidativo mediado por ROS incluye un gran número de moléculas biológicas que causan modificación del ADN, peroxidación lipídica y secreción de citocinas inflamatorias.

Para enfrentar el efecto nocivo del estrés oxidativo, la piel está equipada con mecanismos de defensa antioxidantes que se encargan de 'barrer' los radicales libres de oxígeno e impedir el daño de proteínas y lípidos estructurales. El ambiente de óxido-reducción celular juega un papel doble en la homeostasis cutánea y las enfermedades dermatológicas podrían originarse por un desequilibrio entre los estímulos prooxidantes y los antioxidantes. El sistema antioxidante cutáneo incluye un conjunto de antioxidantes enzimáticos y no enzimáticos. Entre los primeros se incluyen algunas enzimas intracelulares, como la glucosa 6-fosfato deshidrogenasa (G6PDH), la glutatión peroxidasa, la catalasa (CAT), la superóxido dismutasa (SOD) y la mieloperoxidasa. Entre los no enzimáticos, están el alfa-tocoferol, la ubicuinona, el betacaroteno, el ascorbato y el glutatión. Si las enzimas antioxidantes son 
incapaces de controlar el daño oxidativo, los radicales libres de oxígeno inician la peroxidación lipídica de los organelos y las membranas celulares ${ }^{7}$.

Propionibacterium acnes produce factores quimiotácticos para neutrófilos, los que después de fagocitarlo liberan enzimas hidrolíticas que rompen la pared folicular. Al penetrar en la dermis, $P$. acnes estimula al sistema inmunitario, generando una reacción de tipo a cuerpo extraño por los lípidos sebáceos y células pilares y epiteliales, lo cual a su vez conduce a la inflamación. Los radicales libres de oxígeno producidos por los neutrófilos también pueden producir daño celular en el sitio de la inflamación. Además, la acumulación de leucotrieno B-4 inducida por los neutrófilos, parece estar implicada en el proceso inflamatorio del acné ${ }^{8}$. La toxicidad de estas moléculas sobre los queratinocitos es principalmente causada por el anión superóxido que, además de inhibir el crecimiento de la bacteria, ejerce un efecto positivo en la producción de IL-8 ${ }^{39}$. Se ha descrito que la producción de peróxido de hidrógeno está aumentada en los neutrófilos en casos de acné, especialmente en aquellos con acné inflamatorio. También, se ha visto que la disminución del glutatión y de la actividad de la enzima superóxido dismutasa tiene una correlación directa con la gravedad del acné ${ }^{40-42}$.

En los comedones, la proporción de ácido linoléico está notoriamente disminuida y, la del ácido palmítico, significativamente aumentada. El ácido linoleico tiene efectos inhibitorios en algunos tipos de ROS como en el anión superóxido, el peróxido de hidrógeno y el radical hidroxilo, mientras que el ácido palmítico solo disminuye la generación de peróxido de hidrógeno. Así, en los comedones ocurre una sobrecarga de ROS debido a la falta de inhibidores. El escualeno, una molécula específica del sebo humano, parece funcionar como barredor de singletes de oxígeno, evitando la peroxidación lipídica; sin embargo, su peroxidación genera peróxidos de escualeno que tienen efectos comedogénicos ${ }^{7}$.

Los resultados de varios experimentos han demostrado que antibióticos tales como la doxiciclina, la minociclina y el metronidazol suprimen significativamente la actividad de ROS derivados de neutrófilos?

La xantinaoxidasa es una enzima del catabolismo de las purinas que cataliza la conversión de hipoxantina a xantina y de xantina a ácido úrico. En tejidos normales, la xantinaoxidasa existe primariamente como xantina deshidrogenasa, que no genera radicales libres. Durante un proceso inflamatorio, la xantina deshidrogenasa es convertida a xantinaoxidasa, la cual es una fuente biológica de radicales libres de oxígeno. En los comedones, la concentración de ácido linoleico está muy disminuida, mientras que la del ácido palmítico está significativamente aumentada. El ácido palmítico disminuye notoriamente la producción de peróxido de hidrógeno, tanto por parte de los neutrófilos como del sistema xantina-xantinooxidasa; mientras que la quimiotaxis y fagocitosis de neutrófilos, así como la generación de singletes de oxígeno e hidroxilo, por ambos sistemas, no se ven afectadas por este ácido. El aumento de la actividad de la xantinaoxidasa puede contribuir al estrés oxidativo en el acné vulgar8.

El óxido nítrico (NO) es un radical libre generado en las células a partir de la L-arginina mediante la acción de las sintasas del óxido nítrico. Es producido durante respuestas inmunitarias e inflamatorias y es un agente proinflamatorio sintetizado a gran escala en diferentes células estimuladas por citocinas proinflamatorias, como el TNF- $\alpha$ y la IL-1 $\beta$. El óxido nítrico puede reaccionar con el anión superóxido para formar peroxinitrito, que es un poderoso agente citotóxico. Así, el óxido nítrico sintetizado contribuye al daño celular oxidativo. Se han encontrado niveles elevados de productos metabólicos del óxido nítrico en pacientes con acné vulgar. Los retinoides suprimen citocinas que estimulan la producción de óxido nítrico en algunas células ${ }^{8}$.

La destrucción oxidativa de ácidos grasos poliinsaturados de los fosfolípidos, conocida como peroxidación lipídica, puede considerarse como un sello del estrés oxidativo. El malon-dialdehído (MDA), un producto final de la peroxidación de lípidos inducida por radicales libres de oxígeno, se correlaciona bien con el grado de peroxidación. Se han detectado niveles séricos elevados del MDA que indican que la peroxidación de lípidos puede tener un papel importante en la patogénesis de acné ${ }^{8}$.

\section{Receptores activadores de proliferación de peroxisomas en el acné}

En 1990, Issemann y Green clonaron un miembro del grupo de la superfamilia de receptores hormonales nucleares, blanco de diferentes compuestos, que estimula la proliferación de peroxisomas en el hígado de ratón y lo denominaron receptores activadores de proliferación de peroxisomas (PPAR) $)^{72,73}$.

Los PPAR son factores de transcripción activados por ligandos. Actúan al inducir la transcripción de genes, por medio de una secuencia conocida como elemento de respuesta de proliferación de peroxisomas (PPRE) en el núcleo del material genético. Para la activación de los PPAR, primero se involucra una proteína de choque térmico, que envía una señal que modifica el estado de fosforilación de 


\begin{tabular}{|c|c|c|c|}
\hline Subfamilia de PPAR & Función conocida & Localización & Ligandos principales \\
\hline PPAR a & $\begin{array}{l}\text { Catabolismo de ácidos } \\
\text { grasos y metabolismo de } \\
\text { lipoproteínas } \\
\text { Regulación de la respuesta } \\
\text { inflamatoria } \\
\text { Control de la lipogénesis y de } \\
\text { la apoptosis de los sebocitos }\end{array}$ & $\begin{array}{l}\text { Hígado, corazón, riñones, } \\
\text { músculo, grasa parda y } \\
\text { piel }\end{array}$ & $\begin{array}{l}\text {-Fibratos } \\
\text {-WY } 14643, \text { L-165.041 y la } \\
\text { rosiglitazona }\end{array}$ \\
\hline PPAR Y & $\begin{array}{l}\text { Regulador de la diferenciación } \\
\text { de adipocitos y del } \\
\text { almacenamiento de lípidos } \\
\text { Efecto antinflamatorio, } \\
\text { antiproliferativo y promotor de } \\
\text { la diferenciación epidérmica }{ }^{76}\end{array}$ & $\begin{array}{l}\text { Tejido adiposo, colon, } \\
\text { bazo, glándulas } \\
\text { suprarrenales y piel }\end{array}$ & -Fibratos \\
\hline PPAR $\beta / \sigma$ & $\begin{array}{l}\text { Incrementa los niveles de } \\
\text { lipoproteínas de alta densidad } \\
\text { del colesterol (HDL) } \\
\text { Control de la lipogénesis y de } \\
\text { la apoptosis de los sebocitos }\end{array}$ & $\begin{array}{l}\text {-Piel (epidermis) subtipo } \\
\text { prevalente } \\
\text {-Predominio en el acné } \\
\text { inflamatorio }\end{array}$ & $\begin{array}{l}\text {-Fibratos, el ácido } \\
\text { tetradeciltioacético y el } \\
\text { GW } 501516 \\
\text {-WY 14643, L-165.041 y la } \\
\text { rosiglitazona }\end{array}$ \\
\hline
\end{tabular}

TABLA 5. Familias de los receptores activadores de proliferación de peroxisomas (PPAR), localización y funciones conocidas ${ }^{73.77}$

los PPAR y facilita la interacción con el ligando. Para unirse con el ácido desoxirribonucleico (ADN), los PPAR requieren heterodimerización con el receptor de retinoides X; este complejo interactúa con el PPRE, que lleva a una transcripción, y finaliza con la síntesis proteica ${ }^{74}$.

Los PPAR están involucrados en diversas funciones biológicas de la epidermis, como la proliferación y diferenciación de queratinocitos, recuperación y maduración de la barrera epidérmica, actividad de los sebocitos, y diferenciación de los melanocitos ${ }^{75}$. Dado su efecto en el control de la diferenciación de los sebocitos, la modulación de los PPAR puede modificar la producción de sebo y resulta interesante en el desarrollo de tratamiento del acné vulgar ${ }^{75,76}$.

La subfamilia PPAR se subdivide en PPAR $\alpha$, PPAR $\beta / \sigma$ y PPAR $\gamma$, cada una de las cuales tiene diferentes ligandos, genes blanco y múltiples efectos biológicos. Los PPAR se expresan en numerosos tejidos, incluido hígado, riñón, corazón, músculo esquelético, tejido adiposo, endotelio

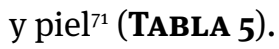

El hallazgo de los activadores PPAR como potenciales moduladores de la lipogénesis, abrió nuevas perspectivas sobre la acción de los sebocitos. Rosenfield, et al., propusieron que los antagonistas de los PPAR reducen la formación de sebo y que pueden ser beneficiosos en el tratamiento del acné. Sin embargo, los diferentes efectos de las isoformas de los PPAR en la lipogénesis aún no están claros ${ }^{77}$. Estos mismos estudios y la comprensión de la similitud existente entre la adipogénesis y la lipogénsis sebácea, llevan a la hipótesis de que los PPAR pueden ser importantes reguladores en la producción de sebo y en el desarrollo del acné $e^{71,78}$. Como se mencionó anteriormente, se han demostrado diferentes subtipos de PPAR en la piel ${ }^{71}$; en el caso de los subtipos de PPAR en el acné, en un estudio reciente se encontró un incremento en la expresión de PPAR $\beta / \sigma$ en el acné inflamatorio, en comparación con el no inflamatorio ${ }^{79}$.

Se considera que la regulación de los PPAR podría modular la inflamación en el acné, al inhibir la expresión de genes proinflamatorios ${ }^{76,80}$. Los resultados de estudios recientes ${ }^{81}$ sugieren que algunos compuestos activadores de los PPAR pueden modular la inflamación, al actuar en los receptores PPAR $\gamma$ de los queratinocitos, pero faltan más investigaciones para profundizar los hallazgos iniciales. Otro estudio ${ }^{76}$ indica el efecto de compuestos producto de las lipoxigenasas, como el leucotrieno B4 (LTB4) en el desarrollo de lesiones inflamatorias del acné y se sabe que este es un ligando de los PPAR $\alpha^{82}$.

La mayoría de los estudios sobre los PPAR y la biología celular de los sebocitos, se han centrado en la lipogénesis como factor fundamental en el desarrollo del acné, pero son pocos las investigaciones que se centran en la apoptosis. Shuster, et al., ${ }^{82}$ encontraron en cultivos de sebocitos inmortalizados que WY 14643, L-165.041 y la rosiglitazona (activadores de los PPAR en los isotipos $\alpha$ $\mathrm{y} \sigma$ ) tienen un efecto anti-apoptosis. Los sebocitos están programados para hacer una diferenciación terminal, 
que lleva a la disrupción de su membrana y a la liberación de su contenido en el infundíbulo. Entraría en consideración si el efecto sebostático de los activadores de los PPAR, no necesariamente se produce a nivel de la lipogénesis, sino por la protección de la apoptosis. El efecto antiinflamatorio de los PPAR, junto con el efecto sebostático, ofrecen un área de investigación en el tratamiento del acné.

\section{Implicaciones de}

\section{Propionibacterium acnes e} inflamación en el tratamiento del acné

Las investigaciones actuales en ciencias básicas y clínicas, incluyendo el análisis de la respuesta inmunitaria innata contra $P$. acnes en la inflamación en el acné y la evaluación de su papel en la generación de comedones, apoyan la supresión de esta bacteria con antimicrobianos como parte del tratamiento del acné. Además, los estudios de los fagos de $P$. acnes que se están llevando a cabo, pueden abrir un nuevo horizonte de tratamientos antibacterianos que no tengan problemas de resistencia antibiótica ${ }^{17}$.

La secuenciación del genoma de $P$. acnes ha confirmado su capacidad de sintetizar porfirinas, las cuales se han usado para facilitar su erradicación cuando se utiliza luz azul intensa (407-420 $\mathrm{nm})$ que lo destruye. Además, la adición de porfirinas exógenas para ser activadas posteriormente por la luz, es la base de la terapia fotodinámica para el acné.

El IGF-1 y el IGF-1R se han identificado como blancos de $P$. acnes en el desarrollo de las lesiones de acné, que confirmaría que esta bacteria no sólo actúa en la fase inflamatoria de la patogénesis del acné sino también en la fase de retención. Esto explicaría por qué los antibióticos y el peróxido de benzoilo tienen un moderado efecto que disminuye la retención al erradicar el micoorganismo.

Los PAM podrían ser potenciales candidatos para el tratamiento del acné al controlar la cantidad de $P$. acnes sin riesgo de desarrollo de resistencia bacteriana. Por ejemplo, se ha demostrado que la combinación de LL-7 y psoriasina presenta un efecto sinérgico contra $P$. acnes ${ }^{36}$, o que los péptidos derivados de la granulisina pueden tener un efecto antibacteriano y modulador de la inflamación ${ }^{83}$. También, se han hecho estudios con un derivado de la indolicidina (familia de catelicidinas), llamado omiganan, uno de los PAM más estudiados clínicamente. La administración tópica de omiganan (MBI 594AN) ha resultado ser prometedora para el tratamiento de acné leve a moderado ${ }^{84}$.
Además, se ha observado que los niveles de metaloproteinasas, que tienen que ver con la formación de cicatrices en el acné, disminuyeron con la mejoría clínica de la enfermedad después del tratamiento. Puesto que se ha podido comprobar que $P$. acnes induce de manera directa la expresión de proMMP-2 en los fibroblastos dérmicos y en los sebocitos, la erradicación del microorganismo durante el tratamiento para el acné puede ayudar a prevenir la formación de cicatrices.

Se ha demostrado que la isotretinoína también afecta las metaloproteinasas de la matriz: reduce la actividad de la MMP-9 y la MMP-13 en el sebo. Este es un efecto que se incrementa con la duración del tratamiento, paralelamente a la mejoría del cuadro clínico ${ }^{69}$.

\section{Moduladores farmacológicos de los receptores de tipo Toll en acné}

La modulación farmacológica de los TLR con moléculas agonistas o antagonistas para el tratamiento de enfermedades dermatológicas, representa un área de gran crecimiento e investigación ${ }^{85}$.

Entre las moléculas que modulan los TLR se encuentran el ácido retinoico, el adapaleno, el cinc y la nicotinamida, entre otras. En recientes investigaciones se han encontrado nuevas moléculas con efecto inhibidor de los TLR, que podrían ser útiles en el acné ${ }^{85}$.

\section{Ácido retinoico}

En varios estudios se ha demostrado el efecto inmunológico de los retinoides; en uno de ellos, se demostró que la tretinoína y el adapaleno inhiben la expresión de TLR-2 en monocitos humanos de voluntarios sanos, cultivados in vitro. A bajas concentraciones de retinoides, casi el $100 \%$ de los monocitos expresaron TLR-2; a altas concentraciones, solo el $20 \%$ de los monocitos expresaron este receptor ${ }^{86}$.

En otro estudio se evaluó la expresión de TLR en monocitos humanos después de 16 horas de exposición a tretinoína (ácido holo-transretinoico o ATRA), encontrándose reducción de TLR-2 y CD14, sin afectar la expresión de TLR-1 y TLR-4. Asimismo, el ATRA indujo disminución de las citocinas inducida por el TLR-2 ${ }^{87}$.

\section{Adapaleno}

Es un derivado del ácido naftoico, considerado un retinoide de segunda generación, cuya función se produce por una unión selectiva con los receptores nucleares del ácido retinoico (RAR), sus tipos RAR gamma en la epidermis y los RAR beta en los fibroblastos. Sus efectos in- 
cluyen también la activación de genes responsables de la diferenciación celular ${ }^{66}$.

La glucoproteína de superficie celular CD1d con funciones de presentación antigénica, participa en la inflamación cutánea y la producción de IL-10; se expresa en queratinocitos de piel normal, con una expresión mayor en aquellos cercanos al estrato córneo rico en lípidos. Los queratinocitos suprabasales son células presentadoras implicadas en la unión de antígenos glucolipídicos que activan las células $\mathrm{NK}^{66}$.

La glucoproteína CD1d tiene una expresión ligeramente disminuida en la piel con acné; el adapaleno induce un aumento en la expresión de esta molécula, facilitando la presentación de antígenos lipídicos y glucolipídicos a las NK; esto es de máxima importancia en la defensa del huésped contra patógenos. El aumento de la expresión de CD1d por el adapaleno puede estimular la actividad de NK contra antígenos bacterianos o lipídicos en la epidermis o el folículo piloso, entre ellos, contra P. acnes.

Los niveles de IL-10 son ligeramente mayores en epidermis de piel normal que en la piel con acné. El adapaleno disminuye la expresión de IL-10 en epidermis de piel normal y con acné, lo cual permite una mejor activación de los linfocitos T. La disminución de la actividad de IL-10 con adapaleno puede modular la respuesta inmunitaria innata y adaptativa ${ }^{66}$.

\section{Nicotinamida}

Es una amina derivada de la vitamina $B_{3}$, que inhibe la producción de citocinas y la quimiotaxis de leucocitos. Se ha utilizado por vía tópica y sistémica en varias alteraciones inflamatorias, incluyendo el acné. En su mecanismo de acción se describe que la nicotinamida inhibe la expresión de IL - 8 de una manera dependiente de la dosis mediante la regulación negativa de las vías MAPK y NF-KB, en queratinocitos activados por $P$. acnes mediante $\mathrm{TLR}_{2}{ }^{88}$.

\section{Opciones terapéuticas con antioxidantes}

\section{TAURINA-BROMAMINA (TAUBR)}

Es el producto fisiológico resultante de la interacción entre el ácido hipobrómico y la taurina, que ha mostrado propiedades antioxidante, antiinflamatoria y antibacteriana. Un hallazgo muy importante en la búsqueda de nuevas alternativas en el tratamiento del acné vulgar ha sido la acentuada sensibilidad de $P$. acnes a laTauBr, por lo que este compuesto podría manejarse como un desinfectante tópico selectivo en el trata- miento del acné. Además, el complejo TauBr inhibe la generación de peróxido de hidrógeno a partir de los neutrófilos activados, que juega un papel muy importante en la reducción de la cantidad y gravedad de las lesiones en el acné. Se han comparado los efectos de la TauBr tópico con clindamicina en gel al $1 \%$ en casos de acné, mostrándose que después de seis semanas de aplicación más del $90 \%$ de los pacientes presentó una mejoría significativa en ambos grupos, sin ningún tipo de efectos adversos. Por lo tanto, la investigación clínica sugiere que la TauBr puede ser usada de manera eficaz y segura como monoterapia o en combinación con otros fármacos en el acné ${ }^{89}$.

\section{EL CINC Y LOS ANTIOXIDANTES}

Han demostrado mejorar las lesiones inflamatorias del acné. Entre los mecanismos de acción del cinc se describen los siguientes:

a. Papel antiandrogénico: efecto inhibitorio de la dehidrotestosterona mediante la 5 -a reductasa de tipo 1.

b. Papel antiinflamatorio: inhibición de la quimiotaxis de polimorfonucleares, inhibición del crecimiento de $P$. acnes; disminuye la producción de TNF- $\alpha$ y de IL-6; activa la capacidad fagocítica de los granulocitos de las células NK; modula la expresión de integrinas; modula ICAM-1 y LFA-3; inhibe el TLR2.

c. Papel antibacteriano

d. Efecto en la proteína fijadora del retinol

e. Antioxidante

f. Evita la resistencia bacteriana ${ }^{90}$.

En un estudio se utilizó un suplemento nutricional que contenía cinc unido a metionina, vitamina $\mathrm{E}$ (antioxidante), vitamina $C$, carotenoides y cromo, tres veces al día durante tres meses. Se obtuvo mejoría estadísticamente significativa a partir de las ocho semanas. Al final del estudio, el $79 \%$ de los pacientes tuvieron mejoría entre el $80 \%$ y el $100 \%$, con disminución significativa en el número de pápulas, pústulas y comedones cerrados, y con adecuada tolerancia. Como el inicio de la acción es tardío, el tratamiento tópico concomitante puede aumentar la eficacia ${ }^{9}$.

\section{Otros agentes con potencial efecto anti-acné}

\section{CBT-SL5}

Los péptidos antimicrobianos pueden ser inducidos en el huésped mediante bacterias patógenas o no pa- 
tógenas. Ellos juegan un papel para el control de patógenos no deseados, como P. acnes.

Enterococcus faecalis SL5, una bacteria ácido-láctica, produce el péptido antimicrobiano CBT-SL5, al cual se le ha encontrado una actividad antimicrobiana de amplio espectro, incluyendo contra P. acnes. A concentraciones de $100 \mathrm{ng} / \mathrm{ml}$ de CBT-SL5, se presentó una reducción significativa de la secreción de IL-8 en queratinocitos expuestos a $P$. acnes. Este estudio demostró un papel potencial del péptido antimicrobiano $\mathrm{CBT}_{-} \mathrm{SL}_{5}$ como una nueva alternativa en el tratamiento del acné. Se ha sugerido que este actúa mediante la interacción con componentes de P. acnes, como antagonista del TLR; sin embargo, su sitio exacto de acción en la vía de los TLR no está claro y requiere futuras investigaciones ${ }^{91}$.

\section{KDTP}

Es un tripéptido derivado del $\mathrm{C}$ terminal de la hormona estimulante de melanocitos $\alpha$ ( $\alpha$-HSM). Se encontró evidencia de un efecto supresor significativo sobre la IL-1B, la IL-6 y la IL-8. Por no haber modelo animal para el acné, es interesante que el KDTP posea actividad antiinflamatoria in vitro. Se demuestra por primera vez que el KDTP tiene un potente efecto antiinflamatorio. El péptido actúa de forma antagonista a IL-1B, presumiblemente por unión a IL-1RI. Consecuentemente, la IL-1B media la formación de ROS, NF-KB y activación de IL-6 e IL-8. La falta de actividad melanotrópica sugiere que este péptido es un candidato promisorio para el tratamiento de muchas enfermedades inflamatorias, no solo las que involucran las glándulas sebáceas ${ }^{81}$.

\section{COMPLEJO TLR2-REGULADOR}

Es un complejo activo capaz de modular la actividad de TLR-2, reduciendo la producción de algunas citocinas proinflamatorias como la IL-8, sin bloquear la liberación de algunos péptidos antimicrobianos como el HBD-2.

Este complejo es una combinación de un extracto de un planta natural de la familia Ombelliferae y un lípido obtenido por biotecnología; estos componentes han demostrado tener actividad antiinflamatoria y su vía de acción es por su efecto inhibidor de TLR-2, demostrado en estudios ex vivo ${ }^{92}$. El estudio consistió en someter piel humana a un extracto inactivo de P. acnes; después de 24 horas de incubación, se evaluó por ELISA la expresión de IL-8. Fueron cuatro grupos: piel sin el extracto microbiano; piel con extracto microbiano únicamente; piel con extracto de $P$. acnes más anticuerpos anti-TLR-2; y, por último, piel con extracto microbiano y complejo TLR-2 regulador. Se encontró una significativa reducción de la secreción de IL-8. Los anticuerpos anti-
TLR-2 inhibieron en forma importante la producción de citocinas IL-8 ( $\mathrm{p}<0,001)$. En el grupo con el complejo TLR2 regulador, se observó una inhibición de la secreción de IL-8, con niveles por debajo de los basales. El valor absoluto de la secreción total obtenida de IL-8 fue de o $\mathrm{ng} / \mathrm{ml}$. Se concluyó que parte de la producción de IL-8 inducida por P. acnes fue dependiente de TLR-2. En las condiciones experimentales evaluadas, el complejo regulador TLR-2 fue capaz de inhibir la producción de IL-8 de los queratinocitos.

\section{REgULACIÓN DE LOS PPAR}

Como se revisó en la sección previa del artículo sobre el efecto de la modulación de la respuesta al estímulo de los PPAR en el acné, dependiendo del subtipo de receptor, su activación o bloqueo puede modificar la producción de lípidos y la apoptosis de los sebocitos, y tener un efecto en la regulación de procesos inflamatorios y de diferenciación celular de la unidad pilosebácea.

\section{Papel de los corticosteroides}

El TLR-2 actúa como receptor de P. acnes, induciendo citocinas y liberación de sustancias como proteasas y hialuronidasas. La activación de TLR-2 por $P$. acnes induce inflamación de la piel con acné, por la activación de varios genes inflamatorios que codifican citocinas, quimiocinas y moléculas de adhesión con invasión de las células inmunitarias.

Los glucocorticoides aumentan la expresión de TLR-2 en cultivos de queratinocitos humanos. La combinación de glucocorticoides con $P$. acnes o citocinas proinflamatorias, actúa de manera sinérgica en el aumento de la expresión de TLR-2. El cortisol aumenta la respuesta inflamatoria en el acné vulgar, produciendo lesiones nuevas y exacerbación de las viejas. Los glucocorticoides aumentan la expresión de TLR-2 en queratinocitos humanos, produciendo cambios inflamatorios deletéreos en el acné vulgar. El estudio sugiere que el aumento de TLR-2 por corticosteroides juega un papel importante, no solo en el acné sino también en la rosácea esteroidea y la dermatitis perioral ${ }^{93}$.

\section{Referencias}

1. Graham GM, Farrar MD, Cruse-Sawyer JE, Holland KT, Ingham E. Proinflammatory cytokine production by human keratinocytes stimulated with Propionibacterium acnes and P. acnes GroEL. Br J Dermatol. 2004;150:421-8.

2. Vowels BR, Yang S, Leyden JJ. Induction of proinflammatory cytokines by a soluble factor of Propionibacterium acnes: Implications for chronic inflammatory acne. Infect Immun. 1995;63:3158-65. 
3. Choi JY, Piao MS, Lee JB, Oh JS, Kim IG, Lee SC. Propionibacterium acnes stimulates pro-matrix metalloproteinase-2 expression through tumor necrosis factor-alpha in human dermal fibroblasts. J Invest Dermatol. 2008;128:846-54.

4. Golub LM, Ramamurthy NS, McNamara TF, Greenwald RA, Rifkin BR. Tetracyclines inhibit connective tissue breakdown: New therapeutic implications for an old family of drugs. Crit Rev Oral Biol Med. 1991;2:297-321.

5. Monk E, Shalita A, Siegel DM. Clinical applications of non-antimicrobial tetracyclines in dermatology. Pharmacol Res. 2011;63:13045.

6. Sato T, Kurihara H, Akimoto N, Noguchi N, Sasatsu M, Ito A. Augmentation of gene expression and production of promatrix metalloproteinase 2 by Propionibacterium acnes-derived factors in hamster sebocytes and dermal fibroblasts: A possible mechanism for acne scarring. Biol Pharm Bull. 2011;34:295-9.

7. Briganti S, Picardo M. Antioxidant activity, lipid peroxidation and skin diseases. What's new. J Eur Acad Dermatol Venereol. 2003;17:663-9.

8. Sarici G, Cinar S, Armutcu F, Altinyazar C, Koca R, Tekin NS. Oxidative stress in acne vulgaris. J Eur Acad Dermatol Venereol. 2010;24:763-7.

9. Krishna S. Innate immunity in the pathogenesis of acne vulgaris. In: Shalita AR, del Rosso JQ, Webster GF, editors. Acne vulgaris. London, UK: American Acne \& Rosacea Society and Informa Health Care; 2011. p. 12,3.

10. Dessinioti C, Katsambas AD. The role of Propionibacterium acnes in acne pathogenesis: Facts and controversies. Clin Dermatol. 2010;28:2-7.

11. Evans CA, Smith WM, Johnston EA, Giblett ER. Bacterial flora of the normal human skin. J Invest Dermatol. 1950;15:305-24.

12. Leyden JJ, McGinley KJ, Mills OH, Kligman AM. Propionibacterium levels in patients with and without acne vulgaris. J Invest Dermatol. 1975;65:382-4.

13. Leeming JP, Ingham E, Cunliffe WJ. The microbial content and complement $\mathrm{C}_{3}$ cleaving capacity of comedones in acne vulgaris. Acta Derm Venereol. 1988;68:468-73.

14. Bruggemann H. Insights in the pathogenic potential of Propionibacterium acnes from its complete genome. Semin Cutan Med Surg. 2005;24:67-72.

15. McDowell A, Valanne S, Ramage G, Tunney MM, Glenn JV, McLorinan GC, et al. Propionibacterium acnes types I and II represent phylogenetically distinct groups. J Clin Microbiol. 2005;43:326-34.

16. Bruggemann H, Henne A, Hoster F, Liesegang H, Wiezer A, Strittmatter A, et al. The complete genome sequence of Propionibacterium acnes, a commensal of human skin. Science. 2004;305:671-3.

17. Farrar MD, Howson KM, Bojar RA, West D, Towler JC, Parry J, et al. Genome sequence and analysis of a Propionibacterium acnes bacteriophage. J Bacteriol. 2007;189:4161-7.

18. Lood R, Morgelin M, Holmberg A, Rasmussen M, Collin M. Inducible Siphoviruses in superficial and deep tissue isolates of Propionibacterium acnes. BMC Microbiol. 2008;8:139.

19. Lood R, Collin M. Characterization and genome sequencing of two Propionibacterium acnes phages displaying pseudolysogeny. BMC Genomics. 2011;12:198.

20. Szabo K, Kemeny L. Studying the genetic predisposing factors in the pathogenesis of acne vulgaris. Hum Immunol. 2011;72:766-73.

21. Koreck A, Pivarcsi A, Dobozy A, Kemeny L. The role of innate immunity in the pathogenesis of acne. Dermatology. 2003;206:96-105.
22. Kim J. Review of the innate immune response in acne vulgaris: Activation of Toll-like receptor 2 in acne triggers inflammatory cytokine responses. Dermatology. 2005;211:193-8.

23. Farrar MD, Ingham E. Acne: inflammation. Clin Dermatol. 2004;22:380-4.

24. Zouboulis CC. Propionibacterium acnes and sebaceous lipogenesis: A love-hate relationship? J Invest Dermatol. 2009;129:2093-6.

25. Kurokawa I, Danby FW, Ju Q, Wang X, Xiang LF, Xia L, et al. New developments in our understanding of acne pathogenesis and treatment. Exp Dermatol. 2009;18:821-32.

26. Grange PA, Weill B, Dupin N, Batteux F. Does inflammatory acne result from imbalance in the keratinocyte innate immune response? Microbes Infect. 2010;12:1085-90.

27. Liu PT, Phan J, Tang D, Kanchanapoomi M, Hall B, Krutzik SR, et al. CD209(+) macrophages mediate host defense against Propionibacterium acnes. J Immunol. 2008;180:4919-23.

28. Gowland G, Ward RM, Holland KT, Cunliffe WJ. Cellular immunity to $P$. acnes in the normal population and patients with acne vulgaris. Br J Dermatol. 1978;99:43-7.

29. Kersey P, Sussman M, Dahl M. Delayed skin test reactivity to Propionibacterium acnes correlates with severity of inflammation in acne vulgaris. Br J Dermatol. 1980;103:651-5.

30. Gallo RL, Nakatsuji T. Microbial symbiosis with the innate immune defense system of the skin. J Invest Dermatol. 2011;131:1974 80.

31. Nakatsuji T, Kao MC, Zhang L, Zouboulis CC, Gallo RL, Huang CM. Sebum free fatty acids enhance the innate immune defense of human sebocytes by upregulating beta-defensin-2 expression. J Invest Dermatol. 2010;130:985-94.

32. Nagy I, Pivarcsi A, Kis K, Koreck A, Bodai L, McDowell A, et al. Propionibacterium acnes and lipopolysaccharide induce the expression of antimicrobial peptides and proinflammatory cytokines/chemokines in human sebocytes. Microbes Infect. 2006;8:2195-205.

33. Bojar RA, Holland KT. Acne and Propionibacterium acnes. Clin Dermatol. 2004;22:375-9.

34. Chronnell CM, Ghali LR, Ali RS, Quinn AG, Holland DB, Bull JJ, et al. Human beta defensin-1 and -2 expression in human pilosebaceous units: Upregulation in acne vulgaris lesions. J Invest Dermatol. 2001;117:1120-5.

35. Nagy I, Pivarcsi A, Koreck A, Szell M, Urban E, Kemeny L. Distinct strains of Propionibacterium acnes induce selective human betadefensin-2 and interleukin-8 expression in human keratinocytes through toll-like receptors. J Invest Dermatol. 2005;124:931-8.

36. Lee DY, Yamasaki K, Rudsil J, Zouboulis CC, Park GT, Yang JM, et al. Sebocytes express functional cathelicidin antimicrobial peptides and can act to kill Propionibacterium acnes. J Invest Dermatol. 2008;128:1863-6.

37. Glaser R, Harder J, Lange H, Bartels J, Christophers E, Schroder JM. Antimicrobial psoriasin $\left(\mathrm{S} 100 \mathrm{~A}_{7}\right)$ protects human skin from Escherichia coli infection. Nat Immunol. 2005;6:57-64.

38. Lemaitre B, Reichhart JM, Hoffmann JA. Drosophila host defense: Differential induction of antimicrobial peptide genes after infection by various classes of microorganisms. Proc Natl Acad Sci U S A. 1997;94:14614-9.

39. Williams MJ, Rodriguez A, Kimbrell DA, Eldon ED. The 18-wheeler mutation reveals complex antibacterial gene regulation in Drosophila host defense. EMBO J. 1997;16:6120-30. 
40. Kim J, Ochoa MT, Krutzik SR, Takeuchi O, Uematsu S, Legaspi AJ, et al. Activation of toll-like receptor 2 in acne triggers inflammatory cytokine responses. J Immunol. 2002;169:1535-41.

41. Akira S, Takeda K. Toll-like receptor signalling. Nat Rev Immunol. 2004;4:499-511.

42. McInturff JE, Modlin RL, Kim J. The role of toll-like receptors in the pathogenesis and treatment of dermatological disease. J Invest Dermatol. 2005;125:1-8.

43. Akira S, Uematsu S, Takeuchi O. Pathogen recognition and innate immunity. Cell. 2006;124:783-801.

44. Webster GF, Leyden JJ, Tsai CC, Baehni P, McArthur WP. Polymorphonuclear leukocyte lysosomal release in response to Propionibacterium acnes in vitro and its enhancement by sera from inflammatory acne patients. J Invest Dermatol. 1980;74:398-401.

45. Williamson E, Garside P, Bradley JA, Mowat AM. IL-12 is a central mediator of acute graft-versus-host disease in mice. J Immunol. 1996;157:689-99.

46. Balashov KE, Smith DR, Khoury SJ, Hafler DA, Weiner HL. Increased interleukin 12 production in progressive multiple sclerosis: Induction by activated $\mathrm{CD}_{4}+\mathrm{T}$ cells via $\mathrm{CD} 40$ ligand. Proc Natl Acad Sci U S A. 1997;94:599-603.

47. Jugeau S, Tenaud I, Knol AC, Jarrousse V, Quereux G, Khammari $\mathrm{A}$, et al. Induction of toll-like receptors by Propionibacterium acnes. Br J Dermatol. 2005;153:1105-13.

48. Makrantonaki E, Ganceviciene R, Zouboulis C. An update on the role of the sebaceous gland in the pathogenesis of acne. Dermatoendocrinol. 2011;3:41-9.

49. Jeremy AH, Holland DB, Roberts SG, Thomson KF, Cunliffe WJ. Inflammatory events are involved in acne lesion initiation. J Invest Dermatol. 2003;121:20-7.

50. Bellew S, Thiboutot D, Del Rosso JQ. Pathogenesis of acne vulgaris: What's new, what's interesting and what may be clinically relevant. J Drugs Dermatol. 2011;10:582-5.

51. Holland DB, Jeremy AH. The role of inflammation in the pathogenesis of acne and acne scarring. Semin Cutan Med Surg. 2005;24:79-83.

52. Taylor M, Gonzalez M, Porter R. Pathways to inflammation: Acne pathophysiology. Eur J Dermatol. 2011;21:323-33.

53. Tsuda K, Yamanaka K, Linan W, Miyahara Y, Akeda T, Nakanishi $\mathrm{T}$, et al. Intratumoral injection of Propionibacterium acnes suppresses malignant melanoma by enhancing Th1 immune responses. PLoS One. 2011;6:e29020.

54. Kitagawa H, Yamanaka K, Kakeda M, Inada H, Imai Y, Gabazza EC, et al. Propionibacterium acnes vaccination induces regulatory $\mathrm{T}$ cells and Th1 immune responses and improves mouse atopic dermatitis. Exp Dermatol. 2011;20:157-8.

55. Knop J, Ollefs K, Frosch PJ. Anti-P. acnes antibody in comedonal extracts. J Invest Dermatol. 1983;80:9-12.

56. Holland DB, Jeremy AH, Roberts SG, Seukeran DC, Layton AM, Cunliffe WJ. Inflammation in acne scarring: A comparison of the responses in lesions from patients prone and not prone to scar. $\mathrm{Br}$ J Dermatol. 2004;150:72-81.

57. Harper JC, Thiboutot DM. Pathogenesis of acne: Recent research advances. Adv Dermatol. 2003;19:1-10.

58. Nakatsuji T, Liu YT, Huang CP, Zoubouis CC, Gallo RL, Huang CM. Antibodies elicited by inactivated Propionibacterium acnesbased vaccines exert protective immunity and attenuate the IL-8 production in human sebocytes: Relevance to therapy for acne vulgaris. J Invest Dermatol. 2008;128:2451-7.
59. Nakatsuji T, Liu YT, Huang CP, Zouboulis CC, Gallo RL, Huang CM. Vaccination targeting a surface sialidase of $P$. acnes: Implication for new treatment of acne vulgaris. PLoS One. 2008;3:e1551.

6o. Ianosi S, Stoicescu I, Ianosi G, Neagoe D, Georgescu CV. The study of CD20 and CD45.Ro antibodies in the inflammatory infiltrate involved in acne and seborrheic dermatitis. Rom J Morphol Embryol. 2007;48:285-9.

61. Burkhart CG, Burkhart CN, Lehmann PF. Acne: A review of immunologic and microbiologic factors. Postgrad Med J. 1999;75:328-31.

62. Szabo K, Tax G, Kis K, Szegedi K, Teodorescu-Brinzeu DG, Dioszegi C, et al. Interleukin-1A $+4845(\mathrm{G}>\mathrm{T})$ polymorphism is a factor predisposing to acne vulgaris. Tissue Antigens. 2010;76:411-5.

63. Caillon F, O'Connell M, Eady EA, Jenkins GR, Cove JH, Layton AM, et al. Interleukin-10 secretion from $\mathrm{CD} 14+$ peripheral blood mononuclear cells is downregulated in patients with acne vulgaris. $\mathrm{Br} \mathrm{J}$ Dermatol. 2010;162:296-303.

64. Tian LM, Xie HF, Yang T, Hu YH, Li J, Wang WZ. Association study of tumor necrosis factor receptor type 2 M196R and toll-like receptor $2 \mathrm{Arg} 753 \mathrm{Gln}$ polymorphisms with acne vulgaris in a Chinese Han ethnic group. Dermatology. 2010;221:276-84.

65. Sugisaki H, Yamanaka K, Kakeda M, Kitagawa H, Tanaka K, Watanabe K, et al. Increased interferon-gamma, interleukin-12p40 and IL-8 production in Propionibacterium acnes-treated peripheral blood mononuclear cells from patient with acne vulgaris: Host response but not bacterial species is the determinant factor of the disease. J Dermatol Sci. 2009;55:47-52.

66. Tenaud I, Khammari A, Dreno B. In vitro modulation of TLR-2, CD1d and IL-10 by adapalene on normal human skin and acne inflammatory lesions. Exp Dermatol. 2007;16:500-6.

67. Abd El All HS, Shoukry NS, El Maged RA, Ayada MM. Immunohistochemical expression of interleukin 8 in skin biopsies from patients with inflammatory acne vulgaris. Diagn Pathol. 2007;2:4.

68. Nagase H, Visse R, Murphy G. Structure and function of matrix metalloproteinases and TIMPs. Cardiovasc Res. 2006;69:562-73.

69. Papakonstantinou E, Aletras AJ, Glass E, Tsogas P, Dionyssopoulos A, Adjaye J, et al. Matrix metalloproteinases of epithelial origin in facial sebum of patients with acne and their regulation by isotretinoin. J Invest Dermatol. 2005;125:673-84.

70. Jalian HR, Liu PT, Kanchanapoomi M, Phan JN, Legaspi AJ, Kim J. All-trans retinoic acid shifts Propionibacterium acnes-induced matrix degradation expression profile toward matrix preservation in human monocytes. J Invest Dermatol. 2008;128:2777-82.

71. Trivedi NR, Cong Z, Nelson AM, Albert AJ, Rosamilia LL, Sivarajah $\mathrm{S}$, et al. Peroxisome proliferator-activated receptors increase human sebum production. J Invest Dermatol. 2006;126:2002-9.

72. Issemann I, Green S. Activation of a member of the steroid hormone receptor superfamily by peroxisome proliferators. Nature. 1990;347:645-50.

73. Kuenzli S, Saurat JH. Peroxisome proliferator-activated receptors in cutaneous biology. Br J Dermatol. 2003;149:229-36.

74. Smith KJ, Dipreta E, Skelton H. Peroxisomes in dermatology. Part I. J Cutan Med Surg. 2001;5:231-43.

75. Michalik L, Wahli W. Peroxisome proliferator-activated receptors (PPARs) in skin health, repair and disease. Biochim Biophys Acta. 2007;1771:991-8.

76. Sertznig P, Reichrath J. Peroxisome proliferator-activated receptors (PPARs) in dermatology: Challenge and promise. Dermatoendocrinol. 2011;3:130-5. 
77. Schuster M, Zouboulis CC, Ochsendorf F, Muller J, Thaci D, Bernd $\mathrm{A}$, et al. Peroxisome proliferator-activated receptor activators protect sebocytes from apoptosis: A new treatment modality for acne? Br J Dermatol. 2011;164:182-6.

78. Rosenfield RL, Kentsis A, Deplewski D, Ciletti N. Rat preputial sebocyte differentiation involves peroxisome proliferator-activated receptors. J Invest Dermatol. 1999;112:226-32.

79. Elmongy NN, Shaker O. Expression of peroxisome proliferator activator receptor beta/delta (PPARbeta/delta) in acne vulgaris. Eur J Dermatol. 2012;22:42-5.

8o. Delerive P, Fruchart JC, Staels B. Peroxisome proliferator-activated receptors in inflammation control. J Endocrinol. 2001;169:453-9.

81. Mastrofrancesco A, Kokot A, Eberle A, Gibbons NC, Schallreuter $\mathrm{KU}$, Strozyk E, et al. KdPT, a tripeptide derivative of alpha-melanocyte-stimulating hormone, suppresses IL-1 beta-mediated cytokine expression and signaling in human sebocytes. J Immunol. 2010;185:1903-11.

82. Devchand PR, Keller H, Peters JM, Vazquez M, Gonzalez FJ, Wahli W. The PPAR alpha-leukotriene B4 pathway to inflammation control. Nature. 1996;384:39-43.

83. McInturff JE, Wang SJ, Machleidt T, Lin TR, Oren A, Hertz CJ, et al. Granulysin-derived peptides demonstrate antimicrobial and antiinflammatory effects against Propionibacterium acnes. J Invest Dermatol. 2005;125:256-63.

84. Wiesner J, Vilcinskas A. Antimicrobial peptides: The ancient arm of the human immune system. Virulence. 2010;1:440-64.

85. Valins W, Amini S, Berman B. The expression of toll-like receptors in dermatological diseases and the therapeutic effect of current and newer topical toll-like receptor modulators. J Clin Aesthet Dermatol. 2010;3:20-9.
86. Vega-Diaz JA, Michel S. Regulation of human monocyte toll-like receptor 2 (TLR-2) expression by adapalene. J Eur Acad Dermatol Venereol. 2002;16:123-4.

87. Liu PT, Krutzik SR, Kim J, Modlin RL. Cutting edge: All-trans retinoic acid down-regulates TLR2 expression and function. J Immunol. 2005;174:2467-70.

88. Grange PA, Raingeaud J, Calvez V, Dupin N. Nicotinamide inhibits Propionibacterium acnes-induced IL-8 production in keratinocytes through the NF-kappaB and MAPK pathways. J Dermatol Sci. 2009;56:106-12.

89. Marcinkiewicz J. Taurine bromamine: A new therapeutic option in inflammatory skin diseases. Pol Arch Med Wewn. 2009;119:673-6.

90. Sardana K, Garg VK. An observational study of methioninebound zinc with antioxidants for mild to moderate acne vulgaris. Dermatol Ther. 2010;23:411-8.

91. Lee YJ, Choi HJ, Kang TW, Kim HO, Chung MJ, Park YM. CBT-SL5, a bacteriocin from Enterococcus faecalis, suppresses the expression of interleukin-8 induced by Propionibacterium acnes in cultured human keratinocytes. J Microbiol Biotechnol. 2008;18:1308-16.

92. Gougerot A MA-M, Lefeuvre L. Dermatoses inflammatoires et Tolllike récepteurs (TLR). Nouv Dermatol. 2009;28:213-9.

93. Shibata M, Katsuyama M, Onodera T, Ehama R, Hosoi J, Tagami H. Glucocorticoids enhance Toll-like receptor 2 expression in human keratinocytes stimulated with Propionibacterium acnes or proinflammatory cytokines. J Invest Dermatol. 2009;129:375-82. 